\title{
Secularism and Fertility Worldwide
}

\author{
Landon Schnabel ${ }^{*}$ \\ Cornell University
}

\begin{abstract}
This study proposes and explores a new fertility determinant: societal secularism. Using countrylevel data from multiple sources $(\mathrm{N}=181)$ and multilevel data from 58 countries in the World Values Survey $(\mathrm{N}=83,301)$, I document a strong negative relationship between societal secularism and both country-level fertility rates and individual-level fertility behavior. Secularism, even in small amounts, is associated with population stagnation or even decline absent substantial immigration, whereas highly religious countries have higher fertility rates that promote population growth. This countrylevel pattern is driven by more than aggregate lower fertility of secular individuals. In fact, societal secularism is a better predictor of highly religious individuals' fertility behavior than that of secular individuals, and this pattern is largely a function of cultural values related to gender, reproduction, and autonomy in secular societies. Beyond their importance for the religious composition of the world population, the patterns presented in this study are relevant to key fertility theories and could help account for below-replacement fertility.
\end{abstract}

Keywords: Secularism; Fertility; Religion; Gender; Reproduction; Attitudes; Values

Last Revised: 6/15/2021

Running Head: Secularism and Fertility Worldwide

Word Count: 11,538

Figures: 5

Tables: 2

Supplemental Materials: 5 figures, 5 tables

\section{THIS PAPER IS FORTHCOMING IN SOCIUS.}

\footnotetext{
* The author is grateful to Andy Halpern-Manners and Brian Powell for exceptional feedback on earlier drafts of this paper. He would also like to thank Keera Allendorf, Conrad Hackett, Pat Hastings, Sam Perry, and Sam Stroope for their insightful feedback. This study benefited from comments at the 2016 meetings of the Population Association of America, American Sociological Association, and Association for the Sociology of Religion, as well as the 2016 Advancing the Demographic Study of Religion conference, and was recognized by the Association for the Sociology of Religion and the religion section of the American Sociological Association. The author is also grateful to the anonymous reviewers and editors at Socius, as well as the anonymous reviewers who worked over multiple rounds of review elsewhere as this paper arrived in its current form. Direct correspondence to Landon Schnabel, Department of Sociology, Cornell University, 323 Uris Hall, Ithaca, NY 14853. Email: schnabel@cornell.edu.
} 
Comte, Marx, Freud, and Durkheim, and other early theorists argued religion was a part of premodern culture and predicted it would decline into obscurity. Secularization theory built on these arguments and assumed, based on religious switching patterns, most of the world population would become nonreligious (Berger 1967; Gorski and Altınordu 2008). Despite extant research on religious differences in fertility (Freedman, Whelpton, and Smit 1961; De Jong 1965; Lenski 1961), this paradigm neglected demographic forces that undermined secularization. Parental religion is the strongest determinant of children's religion (Iannaccone 1998), and individual nonreligious peopleatheists, agnostics, and those who simply have no religious preference or affiliation-tend to have fewer children than those with a religious affiliation (Hackett et al. 2015; Hayford and Morgan 2008; Hout, Greeley, and Wilde 2001). Although secularization theory has persistent proponents, even key architects of the theory like Berger (1967) came to recant what they had said about secularization following a resurgence and radicalization of religion (Berger 1999).

Rather than religious people becoming a smaller proportion of the world population, demographers project that because the religiously unaffiliated have fewer children they will make up a smaller proportion of the world population over time (Hackett et al. 2015; Kaufmann 2010; Skirbekk, Kaufmann, and Goujon 2010; Stonawski et al. 2015). This literature improves on secularization theory by highlighting how individual-level secularity limits fertility behavior and thus constrains secularization, but has thus far neglected potential impacts of societal-level secularity despite secularism being more than just an individual attribute. Culture is transmitted, and religious beliefs and preferences acquired, both vertically (i.e., within families) and horizontally (i.e., peer-topeer within the wider culture) (Bisin and Verdier 2000, 2011). Research on religion and fertility shows how the lower fertility of secular individuals limits vertical transmission of secularism, but has neglected potential demographic limits to horizontal transmission of secularism. The key unanswered question is whether a country-level relationship exists between secularism and fertility 
net of individual-level religion, which would further constrain secularization-due to fewer children being socialized in more secular contexts — and could contribute to below-replacement fertility.

To examine the country-level relationship between secularism and fertility rates and between contextual secularism and individual fertility behavior, I first use data on 181 countries for a global picture of the relationship between secularism and total fertility rates. I then use data from fewer countries (58), but with a multilevel structure and measures of societal values to examine the relationship between societal secularism and individual fertility behavior. I find a strong association between secularism and fertility that operates net of individual religion and appears to be a function of cultural norms related to gender and autonomy. Consequently, fertility patterns limit not only the vertical transmission of secularism, but also horizontal secularization of the global population.

\section{BACKGROUND}

Secularization, Fertility, and Religious Populations over Time

Secularization theory was dominant in the scientific study of religion until the 1980 s, and some continue to argue, based on patterns within economically advanced societies or mathematical modelling of group competition, that the unaffiliated will rise over time (Abrams, Yaple, and Wiener 2011; Bruce 2011; Voas and Chaves 2016). Secular ideas are popular in some societies and current patterns of religious switching advantage the unaffiliated, but some demographers claim the proportion of the world population that is nonreligious will peak and decline by the mid-twenty-first century (Hackett et al. 2015; Kaufmann, Goujon, and Skirbekk 2012; Stonawski et al. 2015). Why are researchers making predictions that counter the popular rhetoric of rising secularism?

The growth or decline of groups is a function of both exogenous factors, such as group switching, and endogenous factors, such as fertility (Hout 2016; Hout et al. 2001; Kaufmann 2010; Scheitle, Kane, and Van Hook 2011). Secularization theory was based on exogenous change: factors external to religious groups, such as religious switching following exposure to new ideas and values, 
will cause shifts in the proportion of people in different religious categories. Secularization theory noted that religious people, at least in some contexts, are more likely to disaffiliate than the unaffiliated are to affiliate. Therefore, as more people deconvert, the world would become increasingly secular. Endogenous change, on the other hand, is driven by factors internal to religious groups, namely fertility as a means to growth from within. A group need not convert people from without to grow: a fertility rate higher than replacement—and whatever rate of "apostasy" the group experiences—will produce growth over generations (Kaufmann 2010). In other words, religious groups seeking growth could focus less on evangelism and simply "be fruitful and multiply.",

Previous research on individual-level affiliation and fertility showed that while exogenous factors matter and can overcome demographic limitations, endogenous growth is foundational to large-scale changes in the religious landscape over time (Hout et al. 2001; Kaufmann 2010; Stark 1996, 2005). Children don't always adopt their parents' religion and can even rebel against it, but parents' religion is the strongest predictor of children's religion—and religious switching is shaped by the religious composition of the society in which it occurs (Bar-El et al. 2013; Iannaccone 1998; Kelley and Graaf 1997; Sherkat and Wilson 1995). Specifically, when vertical cultural transmission from parent to child breaks down and switching occurs, horizontal cultural transmission determines the types of new religious beliefs and preferences people adopt (Bisin and Verdier 2000, 2011). Put simply, the likelihood that someone will adopt a particular trait when switching is based on how common that trait is and the accompanying probability of being exposed to it (Montgomery 2010). Therefore, if more people are born in highly religious societies, even if they leave their parents' religion they are less likely to become secular than if born in more secular societies.

\footnotetext{
${ }^{1}$ Even in the United States where people are rapidly disaffiliating from religion, demographic patterns are helping some groups persist while others shrink (Hout 2016; Schnabel and Bock 2017, 2018).
} 


\section{Contextual Effects and Theories on Below-Replacement Fertility}

As discussed above, a large literature on religion and fertility developed to explain why global secularization never occurred. This research typically focused on the relationship between individual religious affiliation and individual fertility behavior to the neglect of macro factors. Some studies have considered regional or country variation in the relationship between religion and fertility (Hackett 2008; Hubert 2014), but contextual effects of religion on fertility remain understudied (but see Cutright, Hout, and Johnson 1976). Demographic research shows that a variety of contextual effects play an important role in fertility rates, with the diffusion of cultural ideas and norms related to gender roles, contraceptive use, ideal marriage age, and ideal family size precipitating fertility decline (McDonald 2000; Thornton 2001). Illustratively, community-level education can be a key fertility behavior determinant net of individual-level education (Kravdal 2002; Stephenson et al. 2007).

Several theories explain why fertility tends to decline over time and, key to this study, why it varies across countries. Older theories include modernization, wealth flows, ideational change, and mortality decline. These theories assumed fertility rates would eventually balance out at replacement levels. More recently, however, in the era of very low fertility rates in Europe and Asia and newly low fertility rates in other non-Western countries, updated theories have developed. These include second demographic transition (SDT) theory (van de Kaa 1987; Lesthaeghe 2014; Zaidi and Morgan 2017), developmental idealism (DI) theory (Thornton 2001; Thornton et al. 2012), and gender equity theory (McDonald 2000, 2013). Although issues related to secularism are implicit in each of these theories, secularism is rarely considered as a key explanatory factor in societal-level fertility patterns.

Second demographic transition theory builds on and modifies demographic transition theory, which argued mortality decline and modernization would universally lead to replacement fertility (van de Kaa 1987; Lesthaeghe 1983, 2010, 2014). However, fertility in many industrialized societies dropped below replacement, suggesting a new stage in demographic development that van 
de Kaa (1987) labeled the second demographic transition. This fertility imbalance-below rather than above replacement — was theorized to be the result of a rising emphasis on autonomy and selffulfillment, and women's ability to claim total control over their fertility via contraception and abortion. In short, one could use SDT to argue that as secularization and related individualization increase, people — and especially women — will postpone or even forgo childbearing to invest in themselves (e.g., higher education) and their self-actualization (e.g., achieve a better career with higher income).

Developmental idealism is a cultural model focused on how beliefs and values influence fertility (Allendorf and Thornton 2015; Thornton 2001). In short, cognitive schemas and cultural values that idealize development link and valorize democratic governance, an educated citizenry, freedom, gender equality, secularism, and low fertility. Secular culture, therefore, may value and promote autonomy, gender equality, and low fertility. Scholars working in this framework argue and test for how values influence fertility decisions, namely how idealization of development relates to fertility preferences and behavior (Thornton et al. 2012). Similarly to SDT, one could use a DI framework to argue that more secular societies oriented to developmental ideals such as gender equality, reproductive freedom, and autonomous self-fulfillment could be expected to yield lower fertility rates, but the relationship between secularism and fertility remains understudied.

Gender equity theory argues that equity is a key factor in fertility decline (McDonald 2000, 2013). Women's roles, autonomy, and ability to control reproductive processes are important fertility determinants. Gender equity is generally said to reduce fertility, but under certain conditions, including the presence of egalitarian values in which women expect help from men rearing children, the most equitable societies could allow women to better combine career and family plans and, ultimately, have higher fertility than in only moderately gender-equitable societies (Arpino, EspingAndersen, and Pessin 2015; Esping-Andersen and Billari 2015; Goldscheider, Bernhardt, and 
Lappegard 2015; McDonald 2000, 2013). In other words, gender equity will generally decrease fertility but there could be a curvilinear relationship between equity and fertility and/or a distinction between values and material equity. We might, therefore, expect a squared term to matter, or for material equity to facilitate fertility when controlling for values. Although gender equity theory has not focused on religion, other research shows that religion shapes key fertility determinants such as gender and sexuality values and practices, including contraception and abortion (Adamczyk 2008; Hayford and Morgan 2008; Wilde and Danielsen 2015). In fact, Norris and Inglehart $(2002,2011)$ argue that the key divide between different country cultures, which play an important role in fertility, is not democracy, but religion, gender, and sexual liberalization.

\section{Secularism as a Societal-Level Fertility Determinant} I propose that secularism may be a key societal-level fertility determinant underlying and tying together each of these three frameworks. Frequently studied as an individual-level fertility determinant, contextual secularism remains understudied as a potential fertility determinant. A few studies have examined contextual effects of religion on issues related, at least indirectly, to fertility. These studies argue that we should go beyond thinking of religion/secularity only as an individual attribute, and draw on Durkheim’s (1912) argument that religion has a "sui generis" influence on values and behavior, such as suicide, of both religious and secular people (Adamczyk and Felson 2006; Adamczyk and Hayes 2012). According to this argument, religion (and, by the same token, secularism) has a macro-level effect on behavior that operates over-and-above the individuals who contributed to it.

One study working in such a framework found community-level religion has a suppressing effect on premarital sexual behavior (Billy, Brewster, and Grady 1994; also see Adamczyk and Hayes 2012). Adamczyk (2008) showed that although individual religious affiliation influences abortion decisions in the U.S., community-level religious affiliation did not have a strong influence on 
individual-level abortion. Billy and Moore (1992) considered contextual religious adherence in U.S. counties and non-marital fertility behavior, but did not find a strong relationship. Cutright, Hout, and Johnson (1976) directly examined the impact of the strength of Catholic religion in Latin American countries on fertility. They found a negative relationship between country-level religion and non-marital fertility, but a positive relationship with marital fertility, in Latin America.

Contextual secularism, by creating structural and cultural conditions that impact direct fertility determinants like modern contraceptive use, could be a powerful indirect fertility determinant. If secularism is to influence fertility, it will do so through making people more likely to take actions to control births and there several potential pathways, some of which are more direct and some more indirect, through which this could occur. Secularism—and the concomitant attenuated influence of religion-yields specific material conditions known to produce lower fertility rates including but not limited to greater gender equity (which includes greater career opportunities, or at least fewer formal barriers, for women), progressive reproductive policies, and access to both contraceptives and abortion (Schnabel 2016b). Along with these material factors, secularism also facilitates a culture of gender and reproductive autonomy in which it is socially-acceptable, and even encouraged, for women to have careers, for both women and men to seek self-actualization in the here-and-now, and for smaller families to be normalized. In short, I argue that birth rates will be lower when a culture of secularism urges people to view women as more than mothers, makes contraceptives and abortion readily available and culturally accepted, and encourages autonomy and fosters self-fulfillment, all of which will lead, either directly or indirectly, to people taking actions to control births.

My argument about individualization and autonomy in the realms of gender and reproduction synthesizes key aspects of the theories for below-replacement fertility discussed above. Secularism promotes a culture of autonomous self-actualization in the here-and-now central to 
second demographic transition theory. Secular culture could be expected to promote, and in fact be intertwined with, most if not all the key norms of developmental idealism including but not limited to autonomy, sexual freedom, and gender equity. Finally, secularism promotes gender equity, facilitating both gender equitable material conditions and more egalitarian cultural gender values.

\section{Hypotheses}

We know individual-level secularity is negatively associated with individual fertility behavior, but how does societal secularism relate to societal fertility rates? Ecological regressions could yield different results from individual-level regressions and assuming otherwise is to succumb to the reverse ecological fallacy. In fact, scholars have argued that advances in development reverse fertility declines, which could lead us to suspect that more secular countries could have relatively higher fertility rates (Myrskyla, Goldstein, and Cheng 2013; Myrskyla, Kohler, and Billari 2009). Nevertheless, for reasons described below, I expect that more secular countries will have lower fertility rates (as measured by TFR [total fertility rate]):

HYPOTHESIS 1: Country-level secularism is associated with lower fertility rates.

Individual and contextual effects often operate independently and over-and-above one another, and in this case we might expect societal secularism to have both direct and indirect influences on processes related to fertility. For example, more direct and obvious influences include societal norms and even laws about contraception and abortion. More indirect influences include attitudes and values about gender, family, sexuality, autonomy, and self-actualization that are implicated in fertility preferences and behaviors. Past research highlights the impact of religion on these potentially-relevant factors. For example, countries that are more secular have more gender equity (Schnabel 2016b), and countries with more gender equity (e.g., gender parity in education and in the labor market) typically have lower fertility rates (at least up to a point) (McDonald 2000). Other research on contextual effects similarly suggests that whereas secularism promotes secular 
values and individualization, contextual religiosity may promote "traditional, pronatalist values" that produce higher fertility rates (Billy and Moore 1992). Building on these findings, I hypothesize a relationship between country-level secularism and fertility behavior that operates net of individual secularity so that more secular countries-where religious switching is most likely to favor secularism—-have comparatively lower fertility (as measured by CEB [children ever born]). HYPOTHESIS 2: Country-level secularism is associated with lower fertility behavior independent of individual-level secularity.

Gender, sexuality, and familism are key sites for the expression of religious beliefs and values (Edgell and Docka 2007), and secularism contributes to several factors negatively associated with fertility: material gender equity (Schnabel 2016b), egalitarian gender attitudes (Schnabel 2016a; Seguino 2011), and sexuality and abortion attitudes and practices (Adamczyk 2008; Adamczyk and Hayes 2012). Although gender equity theory suggests material gender equity may be the most important intermediary factor (McDonald 2013), McQuillan (2004) argued that values related to gender and sexuality are key reasons why religion influences fertility (also see Hayford and Morgan 2008). In short, secularism promotes autonomy and self-actualization, especially in the realms of gender and sexuality. Therefore, I expect that differences in cultural values and related material conditions in more secular societies will account for a large share of any observed fertility behavior differences (as measured by CEB).

HYPOTHESIS 3: The association between secularism and fertility behavior is in part a function of different cultural conditions and values related to gender, reproduction, and autonomy in more secular societies.

The number of children born into more or less secular societies will shape the future religious composition of the world population. A nation's religious environment plays an important role in the beliefs of its citizens, and their likelihood to become more or less religious above and beyond individual family environments (Bisin and Verdier 2000; Flor and Knapp 2001; Kelley and Graaf 1997; Sherkat and Wilson 1995). If countries with more secular populations have fewer 
Secularism and Fertility Worldwide 10

children then children will be less likely to be exposed to secular ideas, which would limit horizontal transmission of secular culture and exogenous secularization of the global population.

\section{METHODS}

\section{Data}

Data set \#1. Country-level data $(\mathrm{N}=181)$ assembled from multiple sources allow me to examine how the proportion of agnostics or atheists in a country relates to TFR. The 2011 update of the 2008 Association of Religion Data Archives (ARDA) National Profiles provides country-level data from several sources, and I supplement it with others, including the United Nations, World Christian Database, Freedom House, Religion and State Project, Polity IV Project, Heritage Foundation, Correlates of War Project, CIRI Human Rights Data Project, and CIA World Factbook.

Using global data—rather than data that cover some regions, cultures, and religions more thoroughly than others-is important when seeking to examine global patterns. The data I assembled cover the vast majority of the world's countries and allow me to explore the global relationship between secularism and fertility rates. Multilevel data are needed, however, to test the hypotheses that secularism is linked to individual fertility behavior net of individual secularity and that cultural values related to gender, sexuality, and autonomy help explain the relationship.

Data set \#2. The sixth wave (2010-2014) of the World Values Survey $(\mathrm{N}=83,301)$ provides multilevel data from 58 countries across six continents. The WVS consists of nationallyrepresentative surveys of the basic values of the adult general public from a diverse set of countries. These data are well-suited for considering whether and how societal secularism relates to individuals' fertility behavior net of individual secularism, and whether and how societal values operate as intermediary factors between secularism and fertility. I focus on Wave 6, but also examine whether the patterns are shifting over time using waves 1 through 5 . 


\section{Variables \\ Dependent Variables}

The country-level-only portion of this study examines the relationship between the proportion of nonreligious people in a country and that country's 2010-2015 total fertility rate (TFR). The average TFR in the available countries is 2.7 children per woman. Hong Kong has the lowest fertility rate at 1.0 child per woman, and Niger has the highest fertility rate at 6.9 children per woman. The multilevel portion of the study examines the relationship between a country-level secularism scale and individual children ever born (CEB), a measure of cumulative fertility behavior. The average CEB in the 58 World Values Survey (WVS) countries is 1.9. When considering WVS respondents aged 50 and up, and thus past childbearing years in TFR calculations, average CEB is 2.7.

Descriptive statistics are presented in the supplemental materials (Table S1).

\section{Key Independent V ariables}

For the country-level analyses, secularism is measured as proportion agnostic or atheist because it is available across as many countries as possible. ${ }^{2}$ In WVS analyses I measure secularism in four ways: proportion unaffiliated, proportion atheist, aggregate mean religious salience (salience is measured from religion is very important in life $=1$ to religion is not at all important $=4$ ), and aggregate religious services attendance (more than once a week $=1$ to never, practically never $=7$ ). I present scatterplots for each measure individually, and then focus on a scale that combines the four items $(a=.93)$ for which religious salience and attendance are rescaled to range from 0 to 1 to parallel the proportion measures.

\footnotetext{
2 See Adamczyk and Hayes (2012) and Schnabel (2016b) for similar operationalizations of secular populations. World Christian Database estimates_-which the ARDA national profiles use_of proportion secular are consistently conservative across countries (Hsu et al. 2008). I also conducted analyses using 2010 Pew religious composition estimates for proportion unaffiliated and found the same patterns (see Figure S1). Fit statistics prefer the WCD data when secularism is logged.
} 
Secularism and Fertility Worldwide 12

\section{Potential Intermediary Factors}

This study primarily seeks to determine whether a contextual relationship between secularism and fertility exists and, if so, describe it. To also provide a possible explanation, I consider key structural and cultural potential intervening factors closely linked to societal secularism from various sources; structural factors include: gender equity (.60 correlation with logged secularism as shown in Table S2), modern contraceptive prevalence (.55 correlation), and abortion policy (.64 correlation). The Social Watch Gender Equity Index assesses gender equity in three areas: (1) empowerment (percentage of women in technical positions, in management and government positions, in parliaments, and in ministerial posts); (2) economic activity (income and labor force participation gaps); and (3) education (gaps in literacy, primary and secondary school enrollment rates, and tertiary education). The UN tracks contraceptive use prevalence from several sources. The Center for Reproductive Rights has comprehensively tracked countries' abortion policies at the relevant time periods for this study. I use a four-category ordinal measure of abortion policy: (1) absolutely prohibited and exceptions, if any, only for woman's physical health; (2) legal for physical health or for mental health reasons; (3) legal for socioeconomic concerns, as well as for physical and mental health; and (4) legal for any reason.

The WVS allows me to consider cultural factors in the form of aggregated attitudes closelylinked to societal secularism: country-level means of a gender equality index (created by the WVS from three gender attitude measures that address gender equality in the workplace, politics, and education), abortion attitudes (ten-point measure of the justifiability of abortion), and an autonomy and individualization index (measured with six items about qualities that could be encouraged in 
children: determination, imagination, independence, self-expression, faith [reverse coded], and obedience [reverse coded])..$^{3}$

\section{Controls}

Because religious adherence proportions in a country may vary by societal characteristics, I adjust for key societal factors in the country-level analyses. These measures include education, logged per capita GDP adjusted for purchasing power (I tested squared terms for this measure and they were not significant [or close to it], did not alter the results, and did not improve fit statistics), urbanization, globalization (with the KOF index), political system, and region. ${ }^{4}$

In the multilevel analyses, I include individual secularism (scale of same four items in societal secularism scale), individual attitudes regarding gender, abortion, and autonomy (paralleling the societal attitudes), gender (woman=1), marital status ${ }^{5}$ (married or cohabiting=1), age (in yearssome analyses will present patterns within age groups and test overall robustness to age squared, and additional analyses considered further nonlinear terms for age and these did not substantively alter the patterns of interest), education (from [1] no formal education to [9] university-level with degree), and income (self-positioning on a scale of incomes from [1] first step to [10] tenth step). Unfortunately, the World Values Survey data do not include information on age at marriage or childbirth (additional analyses will consider separate age groups). I also adjust for the same key country-level measures from the earlier analyses, using different education and region measures (as described in Table S1) and dropping a measure that seemed potentially relevant but was clearly not important (the globalization index) in the country-level-only analyses.

\footnotetext{
3 This autonomy and individualization index parallels a WVS-created autonomy index with imagination and selfexpression added to what was a four-item index. These items were theoretically relevant to this paper's argument and fit statistics preferred their inclusion. I ran all analyses with the four-item index and the results were substantively equivalent (though the coefficient for the index tended to be slightly larger with these items included).

${ }^{4}$ Results are robust to the inclusion of additional measures not included in the models presented here due to multicollinearity. Figure 2 presents a summary of robustness across thousands of possible models.

${ }^{5}$ Including this control provides a perhaps overly-conservative test of the association between secularism and fertility as it may in some ways be considered a pathway by which secularism could impact fertility.
} 


\section{Analytic Strategy}

This study first uses comparatively complete country-level data on 181 countries from multiple sources to test Hypothesis 1, which proposes a negative association between country-level secularism and fertility rates. I implement multiple imputation (20 datasets) to account for missing data on control variables. ${ }^{6}$ I provide scatterplots of the country-level association and use mulitvariable OLS regression to account for confounders and consider possible pathways.

The second portion of this study uses mixed-effects regression on multilevel data (country is the second level) from the World Values Survey to test Hypothesis 2, which proposes a relationship between country-level secularism and fertility behavior independent of individual secularity. For the multilevel analyses, I implement the same multiple imputation method used for the country-level data. ${ }^{7}$ I first present scatterplots and then multilevel random-intercept generalized linear mixedeffects regression coefficients for secularism on individual fertility behavior (I also considered random-coefficient models that yielded equivalent patterns). The generalized linear mixed-effects results start with just individual-level controls and then add country-level controls to determine whether country-level secularism and individual fertility behavior are associated net of individuallevel religion. I next test for model robustness using a computational approach that considers numerous possible models (Young and Holsteen 2017). I then explore possible explanations for the patterns, considering whether the association is a function of cultural factors linked to secularism and fertility (Hypothesis 3). I then explore variation across subgroups, and test for a cross-level

\footnotetext{
${ }^{6}$ I used Stata's standard regression approach with ordered logistic regression models for ordered measures and logistic regression models for binary measures. Data were missing on five variables with $10 \%$ of data imputed on education, $3 \%$ on GDP, $14 \%$ on the gender equity index, $25 \%$ on modern contraceptive prevalence, and $4 \%$ on the globalization index. Additional analyses using alternative methods for dealing with missing data, including alternative imputation specifications and listwise deletion, yielded substantively equivalent patterns.

$73 \%$ of data were missing and thus imputed on the income scale, $1 \%$ on education, and less than half of $1 \%$ on gender, marital status, and age.
} 
interaction between societal and individual secularism. Finally, I explore the patterns for pertinent subgroups and consider whether the association has changed over time using all waves of the WVS.

For the solely country-level analyses I implement the Sobel-Goodman approach to test for mediation (implemented with the sgmediation Stata user-written program and cross-checked with the khb program) (Kohler, Karlson, and Holm 2011), and for the multilevel data I use a multilevel mediation approach adapted from Krull and MacKinnon (2001) that takes the multilevel structure of the data into account (implemented in Stata with the ml_mediation user-written program).

\section{COUNTRY-LEVEL RESULTS}

\section{Scatterplots}

Figure 1 presents scatterplots of the global bivariate relationship between the proportion of agnostics and atheists in a country and total fertility rate (TFR). As shown in Panel A, the proportion of secular people in a country (measured by proportion agnostic or atheist) is closely related to that country's fertility rate: only countries with about 15 percent or fewer secular people have total fertility rates substantially above replacement. TFRs that produce rapid population growth are found primarily in countries with 5 percent or less secular people.

\section{[Figure-1]}

Summary statistics for these bivariate patterns are clear: the 64 countries $<1 \%$ secular have an average TFR of 3.8, the 66 countries 1-5\% percent secular have an average TFR of 2.5, and the 51 countries $>5 \%$ people have a TFR of 1.8 . Over generations, even small fertility advantages have important implications that give exponential force to fertility rates (advantages are not additive, but multiplicative, over generations). The two-child difference between TFRs of countries $<1 \%$ secular (3.8) and countries $>5 \%$ secular (1.8) is an enormous religious advantage. Of note, this $5 \%$ secular cutoff is not a particularly high level of secularism and countries with higher levels of secularism have even lower TFRs. 
Secularism and country-level fertility are more closely related than can be explained by the individual-level relationship between affiliation and fertility: if individual-level effects wholly explained the country-level patterns we'd expect a modest linear pattern, not a precipitous L-shaped pattern, for the relationship. The linear measure for proportion nonreligious used in Panel A of Figure 1 produces a non-normal distribution, but a log-linear transformation (where the proportion is multiplied by 100 before taking the $\log$ ) in Panel B yields a normal distribution that further emphasizes a clear and strong relationship between secularism and fertility. Additional analyses using other data with another secularism measure-proportion unaffiliated instead of proportion agnostic/atheist—yield the same pattern (see Figure S1).

Based on what we see in Figure 1—some highly religious countries have low fertility rates, but no highly secular countries have high fertility rates_-secularism appears to be a sufficient but not necessary condition for low fertility: a country can have low TFR without secularism, but probably will not have high TFR with secularism. In other words, a country can reach low fertility without a high proportion of nonreligious individuals. This could occur in countries with a strong state church but where traditional religious values do not shape everyday life, or, alternatively, in countries that used to be more secular. As demonstrated by many failed attempts to raise fertility, fertility rates frequently decline but substantial increases are very uncommon. Therefore, once a secular country has low fertility it may not increase even if more people become religious (e.g., Russia). Accordingly, several countries with relatively low secularism and low fertility, such as Poland, are postcommunist.

This study focuses on a global overview, and we would expect some individual countries to deviate from the general pattern. Beyond idiosyncratic variation, secularism could operate differently in countries with different religious cultures. For example, the implications of secularism could be different in Muslim countries than in Christian countries. Panel C of Figure 1 presents the pattern for 108 Christian-majority countries and Panel D for 46 Muslim-majority countries. The direction 
and slope of the relationship is consistent for both, but Muslim countries are less tightly clustered around the fit line than are Christian countries. This difference in residuals could be a result of differential data quality or a real difference between the two, with the link between secularism and fertility rates more predictable for any given Christian country than any given Muslim country.

\section{Multivariable Analyses}

Table 1 presents the association between proportion secular and TFR. More secularism is strongly associated with lower fertility rates, which is partially accounted for by gender equity and abortion policies. The first model presents the bivariate relationship, which is substantial $(b=-5.32 ; p<.001)$ and explains a notable portion of the variation in national fertility rates $\left(R^{2}=.16\right) .{ }^{8}$ Model 2 presents the bivariate relationship when using a logged term for proportion secular $(b=-.50 ; p<.001){ }^{9}$ which is preferred by fit statistics $\left(R^{2}=.43\right.$ when using the logged term) and even just a cursory glance at the scatterplots. ${ }^{10}$ The third model introduces controls. Although some of the controls (e.g., education and proportion urban) are powerful fertility predictors, a strong relationship between secularism and fertility persists $(b=-.17 ; p<.001)$. Gender and sexuality factors-gender equity, modern contraceptive prevalence, ${ }^{11}$ and abortion policy—provide an explanation for some but not all of the relationship that persists after introducing controls. Following gender equity theory, I considered a squared term for gender equity and elected to not include it in the final model because

\footnotetext{
8 Additional analyses considered the patterns among majority-Christian countries ( $>50 \%$ Christian), majority-Muslim countries, and countries where neither is a majority. As noted in the text, the coefficient for all countries is -5.3 . In Christian-majority countries it is -6.6, in Muslim-majority countries -5.7, and in other countries -3.2.

${ }^{9} \mathrm{I}$ also considered quantile regression with the untransformed secularism measure and found it mattered more at lower levels. When using the transformed (logged) measure, patterns are consistent across levels in quantile regression. ${ }^{10} \mathrm{I}$ also tested a logged term for fertility and arrived at substantively equivalent results.

${ }^{11}$ I focus on modern rather than total contraceptive prevalence because modern contraception (e.g., pill, IUD, and injection) is theorized to be an intervening factor but traditional contraception (e.g., rhythm method, withdrawal, or lactational amenorrhea) isn't. Whereas modern contraception is strongly and positively linked to secularism, traditional contraception is weakly and negatively associated with secularism. Countries with low secularism and low fertility, such as Poland, tend to have higher traditional contraceptive prevalence and lower modern contraceptive prevalence.
} 
it was not significant (or close to significant). ${ }^{12}$ Mediation analyses demonstrate the intervening factors are significant and substantial mediators.

[Table-1]

The solely country-level results demonstrate that higher proportions of nonreligious people are strongly associated with lower fertility rates, and that this relationship is in part a function of the gender equity, modern contraceptive use, and abortion policies of more secular countries. These findings lay out a broad picture for most of the world's countries_-including many developing nations that tend to not be covered by cross-national data collection efforts-and provide clear support for the hypothesis that country-level secularism is associated with fertility rates.

\section{WORLD VALUES SURVEY RESULTS}

\section{Scatterplots}

The analyses presented above included as many countries as possible, but multilevel models are needed to determine whether secularism is linked to individual-level fertility behavior net of individual secularism. Although the analyses presented earlier have a better measure of fertility (TFR vs. CEB), the WVS provides additional (and arguable better) measures of secularism.

Before turning to multilevel models, I first show the general pattern for the country-level association between secularism (measured in four ways) and aggregate fertility (measured with average CEB) behavior for the WVS in Figure 2. Panels A and B of Figure 2 demonstrate a strong, negative, and more linear association between proportion unaffiliated—and then proportion atheist - and aggregate CEB. Panels $\mathrm{C}$ and D demonstrate a similar association for aggregate religious salience and aggregate religious service attendance. These scatterplots suggest that the pattern for proportion atheist or agnostic shown above is likely a function of an underlying factor of

\footnotetext{
12 Patterns for the other variables aren't altered by the inclusion of the squared term for gender equity.
} 
general societal secularism proxied by each of the aggregate secularity measures. Therefore, I created a secularism scale comprised of the four individual measures.

[Figure-2]

Plotting this secularism scale against average CEB (see Figure S2) demonstrates a clear and strong relationship that parallels what we saw in Figure 1. But it also highlights an issue with CEB as a fertility measure: age. Young people have not had all the children they will have throughout their lifetime. For example, it appears countries such as Nigeria with known high total fertility rates have comparatively low average CEB because higher fertility produced younger populations in those countries. While later multilevel models will control for age, a simple solution is to focus on those past childbearing years. Figure 3 presents the country-level relationship between aggregate secularism and CEB among people 45 or older. ${ }^{13}$ When focusing on people with completed CEB, the relationship is now even stronger. And whereas there were several outliers before restricting age, there are fewer outliers when focusing on those past prime child-bearing years. Instead, we simply see a pattern of some post-communist countries having lower than predicted CEB-possibly driven by rising rather than declining average religiosity in some of those contexts, and the possibility that once fertility rates have declined increased religiosity after-the-fact may not effectively bring them back up ${ }^{14}$ - and two idiosyncratic outliers, Jordan and China, that contribute to the lowess fit line deviating from the linear fit line. ${ }^{15}$

\footnotetext{
13 The cutoff for calculating TFR is 50 or older, but I opted to present 45 or older because relatively few people have children after 45 and I was able to retain a larger sample (especially important in countries with relatively small older populations). I also considered other age cutoffs (including 50+) and found substantively equivalent patterns.

14 The TFR results followed a similar trend where some of the same post-communist countries had lower than expected TFR, but it is also possible that because CEB is a more retrospective measure that post-communist countries could have religion-driven increased fertility in the future.

${ }^{15}$ China is an interesting case given discussions about the differentially-enforced one-child-policy: rather than China having a lower CEB than predicted, as might be expected on the basis of the policy, average CEB in China is higher than predicted. It's possible that rather than an outlier, China is an example of what happens at the highest levels of secularism when there are fewer religious people for secularism to impact (as will be shown, there is a cross-level
} 
[Figure-3]

\section{Multilevel Multivariable Analyses}

Table 2 presents generalized linear mixed-effects coefficients from multilevel models using the World Values Survey. ${ }^{16}$ These results demonstrate two key patterns: 1) the association between country-level secularism and individual-level CEB operates net of individual secularism and both individual-level and country-level controls, and 2) the more progressive societal values in the realms of gender, reproduction, and autonomy in more secular countries help account for this relationship.

\section{[Table-2]}

Model 1 in Table 2 shows a large coefficient for secularism: this 1.9 child secular CEB disadvantage at the country level is much larger than the 0.2 child disadvantage for individual-level secularism. The 1.9 child disadvantage is about as large as the mean CEB of 1.8 in this ageunrestricted WVS sample. Previous research emphasized the importance of individual-level secularism, but Model 1 indicates it is not nearly as important as country-level secularism. Model 2 adds key country-level controls that attenuate but do not explain away the association between country-level secularism and CEB.

Recent research highlights the importance of considering alternate models to explore the robustness of a chosen model's estimates. After deciding on the model I thought best estimated the relationship between societal secularism and individual-level CEB when controlling for both individual and country-level factors, I conducted additional analyses with a number of alternative models. Specifically, I estimated all permutations of models with all combinations with and without each of the individual and country-level variables in Model 2 and some additional variables that

interaction so that secularism matters more for religious people than secular people). The inclusion or exclusion of outliers does not substantively alter the multivariable results presented below, which will focus on all available countries.

${ }^{16}$ Multilevel Poisson models demonstrated equivalent patterns. 
Secularism and Fertility Worldwide 21

could have been included Model $2 .{ }^{17}$ Figure 4 summarizes estimates from 49,152 possible models. In all 49,152 models there was a negative and significant relationship between secularism and CEB. The preferred model's coefficient (1.43) was very close to the mean of the estimates from all models

[Figure-4]

Having demonstrated the strong and robust relationship between societal secularism and individual-level fertility behavior over-and-above individual secularism (Hypothesis 2), we now turn possible explanations for the relationship. Models 3-5 of Table 2 consider potential intermediary factors theoretically expected to result from secularism and subsequently influence fertility behavior. Model 3 shows that accounting for relevant material conditions and policies that proxy a country's reproductive structure (gender equity, modern contraceptive prevalence, and abortion policy) attenuates the coefficient from 1.4 to 1.1. Structure matters, but culture—as measured by societal norms in the realm of gender, reproduction, and individualization strongly linked to secularism (see Table S3) — may be particularly important in the relationship between secularism and fertility. Model 4 shows societal gender and abortion norms further attenuate the link between secularism and fertility behavior, reducing the coefficient from 1.1 to .8. Finally, Model 5 introduces autonomy norms. In this model with all the expected intermediary factors, there is no longer a significant relationship between societal secularism and CEB. In other words, structural and cultural factors related to gender, sexuality, and autonomy ${ }^{18}$ — and especially gender and autonomy norms implicated

\footnotetext{
${ }^{17}$ Because estimates without them would be largely meaningless for our purposes here, I retained controls for individuallevel secularism and age in all models. The additional potential variables I included in the models summarized in Figure 2 are globalization, political identity, and squared terms for GDP and age. Further additional analyses also considered more measures - such as a country's majority religion, which is highly collinear with secularism especially when the religiously unaffiliated are the majority religious group — and provided similar patterns but inflated multicollinearity. 18 These explanatory measures likely tap into relevant unmeasured factors (e.g., fertility intentions), and alternative measures could be used to proxy these factors. For example, additional analyses with an aggregate measure of the proportion of women identifying as housewives - strongly correlated with gender equity (a part of which is women's workforce opportunity) and gender attitudes (including attitudes toward women working) — show this measure could also be used to help explain the association between secularism and fertility.
} 
in wanting people, and especially women, to have control over their lives and privileging self-

actualization over large traditional families—seem to largely explain the relationship between societal secularism and individual fertility.

When examining any global pattern, it's important to consider heterogeneity across a variety of factors. I explored patterns across a number of subgroups. Table S4 summarizes patterns for a few of these subgroups (and also summarizes analyses with alternative secularism measures and different approaches to missing data). The general pattern holds across subgroups (i.e., secularism is negatively associated with fertility across groups), but the results summarized in Table S4 highlight some variation in the strength of the association. The pattern is similar among women and men, but there does appear to be some age variation: Coefficients (and mean CEB) are notably smaller among younger people who have not completed their fertility. Considering the world's two largest religious groups, Christians and Muslims, separately demonstrates that although the overall pattern is similar for both groups, the intermediary factors do more to explain the relationship among Christians than among Muslims. ${ }^{19}$

The clearest variation in the strength of the relationship is between those affiliated with any religion and the religiously unaffiliated: societal secularism is a very strong predictor of fertility behavior among the affiliated, whereas the unaffiliated have a similarly low number of children regardless of where they live. I further explored this pattern by conducting a cross-level interaction between societal- and individual-level secularism. As shown in Figure 5, highly secular people are not

\footnotetext{
${ }^{19}$ Further analyses examining separate Christian categories demonstrated the relationship between secularism and fertility is particularly strong among Catholics and Protestants, and weaker among the Orthodox (who have overall lower CEB and are disproportionately located in postcommunist contexts). I also considered the patterns among other religious groups. Some groups such as Taoists were located in just one or a few countries, which obviously limits any consideration of country-level variation. Additional religious affiliations present across at least half the countries were Jewish, Hindu, and Buddhist. The general pattern holds among both Jews (among whom the coefficients are a bit larger than for the full sample) and Buddhists (among whom the coefficients are a bit smaller, and for whom the intermediary factors do not explain the relationship between secularism and individual-level fertility behavior). Among Hindus, the vast majority of whom live in India, there is not a significant relationship between secularism and CEB (though the nonsignificant coefficient is in the same direction as found among other groups).
} 
heavily influenced by how religious of a country they are in: secular people have relatively few children regardless of whether they are in more or less secular societies (also see Table S5). But the more religious a person is, the more societal secularism matters: very religious people tend to have a large number of children in very religious societies, but few children in more secular societies. Subsequently, we see a large gap between the number of children religious and secular people have in highly religious countries, but in more secular societies everyone shifts toward the secular consensus of having relatively few children. In short, the strong relationship between societalsecularism and individual-CEB is driven by the fertility patterns of more religious people.

\section{[Figure-5]}

This focused on Wave 6 of the WVS (2010-2014), which demonstrated a strong relationship between secularism and individual fertility behavior. Does the association between secularism and fertility hold for the other waves? Figure S3 shows the association between secularism and fertility behavior for each of the six waves $(\mathrm{N}=312,091)$ using proportion unaffiliated as the secularism measure (which was more consistently available across countries in all waves).

In Wave 1 (1981-84) the association between secularism and fertility behavior was not significant. In Wave 2 (1990-94), it was significant, but the estimated CEB difference between hypothetical wholly religiously affiliated and wholly unaffiliated countries was only .6. In Wave 3 (1995-98), the difference was 1.2. Despite each wave including a different set of countries, from Wave 4 (1999-2004) onward the estimated difference has been the same: 1.4 children. Further analyses considered a three-level model with individuals clustered within waves within countries. In this three-level model, the estimated CEB difference is .7 $(p<.001)$. Although the relationship between country-level secularism and individual fertility behavior net of individual nonreligion has 
not always been strong in the WVS, it has been substantial and stable since the 1990s, which is when the phenomenon of a few countries reaching "lowest-low fertility" developed. ${ }^{20}$

In short, the data demonstrate a strong relationship between country-level secularism and fertility (Hypothesis 1) that operates over-and-above individual religious affiliation (Hypothesis 2) and appears to be a function of cultural differences, especially in the realms of gender and autonomy, between more secular and more religious societies (Hypothesis 3). In a cross-level interaction between country- and individual-level secularism, the relationship is stronger among more religious respondents than among less religious respondents. This relationship between secularism and fertility appears to have become more pronounced in the 1990s, and has been consistently large since the late 1990s through Wave 6 of the World Values Survey.

\section{DISCUSSION}

Societal secularism is a powerful predictor of both country-level fertility rates and individual-level fertility behavior. It is a more powerful predictor than individual-level secularism, which research highlights as a key predictor (Kaufmann et al. 2012; Skirbekk et al. 2010; Stonawski et al. 2015). The relationship is driven by the strong association between secularism and the fertility patterns of religionists—-secularists have few children regardless of where they live. The results hold across various subgroups, specification strategies, alternate measures of secularism and fertility, and when controlling for individual- and country-level factors including proxies for "modernization." Moreover, the power of societal secularism as a fertility determinant operates net of individual-level religion and has been stable since the 1990s, which is when the phenomenon of "lowest-low fertility" (TFRs under 1.3) developed (Kohler, Billari, and Ortega 2002). This study's primary

${ }^{20}$ It's important to note compositional differences between earlier and later waves of the WVS. Earlier waves had fewer countries and less diversity, so the larger differences found in later waves could be due to the broader range of countries in later waves. 
purpose was to test and describe a global contextual association between secularism and fertility, but I also theorized that the relationship is a function of cultural factors-particularly in regard to gender, reproduction, and autonomy—-fostered by secularism that subsequently impact fertility.

Secular countries promote greater autonomy for women, their lives, and their bodies. But more religious countries tend to have cultural values_-familism, drive to family formation, idealized fertility, and even explicit injunctions to "be fruitful and multiply" — that promote pronatalist preferences, a reluctance to use modern contraceptives and abortion, and generally greater control over women, their lives, and their bodies (Bearman and Bruckner 2001; Billy and Moore 1992; Edgell and Docka 2007; Gallagher 2003; De Jong 1965; Philipov and Berghammer 2007). As I demonstrated, material conditions and especially cultural values related to gender, reproductive, and general autonomy largely explain differential fertility rates in more or less secular countries.

Why would societal secularism more strongly predict the individual-level fertility behavior of more religious people than that of more secular people? Secularism, and related shifts in gender values and equity, creates opportunities for all women, including religious women, to be more than just mothers. Once women are pursuing careers and other opportunities, having fewer children becomes more advantageous. In addition to making it more desirable to have fewer children, secularism also promotes ways to control fertility. Reproductive control is a direct cause of lower fertility rates, and we might expect normalization of and access to methods for controlling fertility (e.g., contraceptives and abortion) to impact religious individuals more than secular individuals (who are already breaking social norms by being secular in religious societies, and could be less constrained by social norms opposing reproductive control). Even if religion collectively tends to stigmatize and limit access to these family-planning methods, individual religious people often have pragmatic reasons to use them-especially when they live in countries with gender norms that support women working outside the home. Put simply, secularists could be expected to control their 
reproduction regardless of where they live, and religionists could be expected to use contraceptive methods when three conditions are met: 1) limiting children would be beneficial (or at least help avoid costs) in some way, 2) effective contraceptive methods are readily available, and 3) these methods are seen as a culturally-acceptable option (i.e., they are not stigmatized).

Alongside such theoretical arguments, patterns for the intermediary factors used to explain the relationship between secularism and fertility behavior shed empirical light on the cross-level interaction: the intermediary factors are themselves more strongly related to the CEB of more religious people. For example, the impact of country-level gender norms on CEB is about ten times as large among the religiously affiliated as the religiosity unaffiliated. As was the case with contextual secularism, secularists have few children regardless of the gender or autonomy norms of where they live, but religionists have fewer children in more gender equal and autonomy-valuing countries. In short, secular cultures tend to have a broad set of progressive societal norms about gender, family, and reproduction - including gender egalitarianism, sex for pleasure rather than reproduction, and self-actualization - that lead to lower fertility preferences and greater readiness to use effective family planning methods across the population while secular individuals tend to live according to these values regardless of where they live (Adsera 2006; Buber-Ennser and Skirbekk 2016; Hayford and Morgan 2008). ${ }^{21}$ And when secular norms predominate, religious people may simply be more susceptible to shifting toward the secular consensus of having relatively few children.

This study is compatible with theories — second demographic transition, developmental idealism, and gender equity — formulated following the development of very low fertility in the 1990s (when the association between country-level secularism and individual-level fertility became most pronounced). Issues related to secularism are baked into these theories, and this study has

\footnotetext{
21 Additional analyses with the 2012 ISSP gender and family module, which unfortunately did not include CEB, demonstrated that religious people report substantially lower ideal family size norms in more secular countries, but that unaffiliated people generally report low ideal family size norms across countries.
} 
made explicit the role of secularism in global fertility patterns. Consistent with second demographic transition theory, religion, values, and people's ability to control fertility to attain autonomy and selffulfillment are important fertility determinants. Consistent with developmental idealism theory's focus on culture, cultural norms and values_-and related policy_are important fertility determinants. The findings are also consistent with gender equity theory, with the WVS analyses highlighting the importance of gender values for lower fertility and the potential for material gender equity to, under the right circumstances, facilitate higher fertility. ${ }^{22}$

Can a country's fertility rate decline without secularization? Will fertility rates increase in countries like Russia and China whose populations are becoming more religious? And what about individual countries like Iran, where a theocratic government essentially endorsed and facilitated the spread of contraception that led to a drop in fertility rates? ${ }^{23}$ Secularism is a sufficient but not necessary condition for low fertility: some highly religious countries have low fertility rates, but highly secular countries do not have high fertility rates. Therefore, a country can reach low fertility without secularism, but once a secular country has low fertility we would not necessarily expect a large increase in fertility if it becomes more religious. ${ }^{24}$ As demonstrated by historical patterns and strategic attempts to increase fertility rates in some low fertility contexts, fertility rates frequently

\footnotetext{
22 These patterns are consistent with both an empirical critique of gender equity theory that found equity indices are weak fertility determinants (Mills 2010) and the principles behind gender equity theory (McDonald 2000). Even if gender equity indices are not as important as might be expected based on gender equity theory, gender-related policies and attitudes are strongly and independently associated with lower fertility and material equity making it easier for women to get support and balance self-fulfillment and childbearing.

${ }^{23}$ Iran is an interesting case where very high levels of religiosity apparent on some surveys are likely at least in part the result of social pressures to say one is religious. In fact, Iran's declining fertility rates may be coinciding with a quiet secularization. Survey methods that seek to remove perceived social pressure (e.g., done anonymously online) indicate Iran is less religious than it appears on surveys like the WVS conducted in person, sometimes in front of others, and by organizations that people may worry could make their responses available to the theocratic government (Arab and Maleki 2020).

${ }^{24}$ Furthermore, we might question the extent and meaning of increased contextual religiosity as many cases of rising societal religiosity are the result of the end of top-down state-sponsored secularism in postcommunist contexts rather than fading bottom-up cultural secularism.
} 
make substantial moves downward but substantial moves upward are very uncommon. ${ }^{25}$ Moreover, this study presents a broad global pattern in which secularism is closely linked to, but not a perfect predictor of, fertility rates. As with most global patterns, we would certainly expect it to apply better in some places than others, to be biased toward more common cultures (e.g., Christian and Muslim societies), and for idiosyncrasies to lead some countries to deviate from the trend line.

The data in this study were well-suited to uncover a strong global relationship between secularism and fertility measured as both societal rates (TFR) and individual behavior (CEB). This study, like most other demographic research, is limited, however, by its greater ability to describe relationships than to establish causality or fully explain exactly why the relationships exists. ${ }^{26}$ Although regularly used in demographic research, TFR and CEB measures have limitations that should be acknowledged. For example, changes in tempo across cohorts can cause period TFR to be biased downward relative to cohort TFR. Similarly, differences in the age schedule of fertility across countries can affect $\mathrm{CEB}$, which is further limited by being retrospective. Sensitivity analyses such as those presented in the supplemental materials for specific age groups-which corroborate the patterns in the paper-can help address these limitations to some extent, but these measurement issues are somewhat unavoidable and likely introduce some level of bias. Among other limitations, the WVS does not examine the same set of countries over time. Nevertheless, the measures provided by the World Values Survey are suggestive that cultural norms-especially in the realms of gender, reproduction, and individualization — are important factors in the association between

\footnotetext{
${ }^{25}$ For example, Poland was once communist, is now more religious than surrounding countries, and modern contraceptive methods are comparatively uncommon in Poland. But even if religion keeps people from using some methods of reproductive control (e.g., modern contraception or abortion), if low fertility norms are in place people can still find ways to prevent childbirth. Illustratively, there are high levels of traditional contraceptive methods in Poland. ${ }^{26}$ Another limitation is the possibility of contextual misspecification Hauser (1970) cautioned against. Nevertheless, there are theoretical reasons to suspect that secularism does have a real social impact as illustrated by Hauser's own work on religion and fertility. Janssen and Hauser (1981) stated the possibility of "secular forces affecting the fertility of all segments of the society" (p. 511), which is supported by the present finding that religious people have fewer children in more secular countries because of cultural differences related to gender and reproduction.
} 
secularism and fertility behavior. Future research should further unpack these patterns and may find that secularizing processes can help explain the rise and spread of very low fertility.

Despite some limitations, this study demonstrates a clear pattern with important demographic implications: secularism in a country is associated with population stagnation or even decline (absent substantial immigration), whereas highly religious countries could be expected to have growing populations and an increasing share of the world population. Immigration could counteract population stagnation or decline in highly secular countries, but-importantly in terms of demographic limitations to secularization-immigrants tend to be more religious than native-born populations in secular societies. In fact, migration is already a key factor in population increase in many secular countries including Britain, France, Austria, and Nordic countries, and in addition to bolstering population size this immigration elevates religiousness and fertility rates.

Beyond its implications for demography, this study speaks directly to core questions in the scientific study of religion. For example, what is the future of religion? Can we expect the world to become less religious, more religious, or remain in some sort of stable equilibrium? One of the primary ways scholars determine whether the world is secularizing is to consider whether younger people are less religious than older people. In many countries, younger people are less religious than older people. As illustrated in Figure S4 in the supplement, that pattern is confirmed here: if you look within all countries in the World Values Survey and take the average, younger people are much less religious than older people. But if you look across the global population as represented by the pooled World Values Survey sample, younger people are actually much more religious than older people as also shown in Figure S4.

A disproportionate percentage of the world population is born in highly religious countries with growing populations and young average ages. In contrast with the young and rapidly growing populations of highly religious countries, the most secular countries have low fertility rates and aging 
populations (see Figure S5). Yes, religious switching patterns may prefer secularization, but religious people have fewer children in contexts where their children will be exposed to secularism. Because of its negative relationship with fertility, societal secularism is self-constraining with clear implications for secularization theory and other paradigms that seek to predict the future of religion. Rather than declining into obscurity, religion's importance in global society could be expected to persist (and perhaps even rise) over time.

Studies focused solely on individual patterns appear to have underestimated how demographic patterns limit secularization. Secularization is constrained not only by secularists having fewer children, but also by religionists having fewer children in countries where their children will be frequently exposed to secular people and ideas. Despite the strong link between secularism and fertility that limits secularization of the global population, secularism is on the rise in some contexts, and especially in contexts with culture that spreads to other parts of the world. Even if horizontal transmission of secular culture is limited within countries, in an increasingly globalized world horizontal cultural transmission of secularism could occur across countries and potentially overcome the demographic limitations to secularization.

\section{REFERENCES}

Abrams, Daniel, Haley Yaple, and Richard Wiener. 2011. "Dynamics of Social Group Competition: Modeling the Decline of Religious Affiliation.” Physical Review Letters 107(8):1-4.

Adamczyk, Amy. 2008. "The Effects of Religious Contextual Norms, Structural Constraints, and Personal Religiosity on Abortion Decisions.” Social Science Research 37(2):657-72.

Adamczyk, Amy, and Jacob Felson. 2006. "Friends' Religiosity and First Sex." Social Science Research 35(4):924-47.

Adamczyk, Amy, and Brittany Hayes. 2012. "Religion and Sexual Behaviors: Understanding the Influence of Islamic Cultures and Religious Affiliation for Explaining Sex Outside of Marriage." American Sociological Review 77(5):723-46.

Adsera, Alicia. 2006. "Religion and Changes in Family-Size Norms in Developed Countries." Review of Religious Research 47(3):271-86.

Allendorf, Keera, and Arland Thornton. 2015. "Caste and Choice: The Influence of Developmental Idealism on Marriage Behavior." American Journal of Sociology 121(1):243-87.

Arab, Pooyan Tamimi, and Ammar Maleki. 2020. "Iran's Secular Shift: New Survey Reveals Huge Changes in Religious Beliefs." The Conversation. Retrieved May 6, 2021 
Secularism and Fertility Worldwide 31

(https:/ / theconversation.com/irans-secular-shift-new-survey-reveals-huge-changes-inreligious-beliefs-145253).

Arpino, Bruno, Gøsta Esping-Andersen, and Léa Pessin. 2015. "How Do Changes in Gender Role Attitudes towards Female Employment Influence Fertility? A Macro-Level Analysis.” European Sociological Review 31(3):370-82.

Bar-El, Ronen, Teresa Garcia-Munoz, Shoshana Neuman, and Yossef Tobol. 2013. "The Evolution of Secularization: Cultural Transmission, Religion and Fertility-Theory, Simulations and Evidence." Journal of Population Economics 26(3):1129-74.

Bearman, Peter, and Hannah Bruckner. 2001. "Promising the Future: Virginity Pledges and First Intercourse." American Journal of Sociology 106(4):859-912.

Berger, Peter. 1967. The Sacred Canopy: Elements of a Sociological Theory of Religion. New York: Anchor.

Berger, Peter. 1999. The Desecularization of the World: Religion and World Politics. Grand Rapids, MI: Eerdmans.

Billy, John, Karin Brewster, and William Grady. 1994. "Contextual Effects on the Sexual Behavior of Adolescent Women.” Journal of Marriage and Family 56(2):387-404.

Billy, John, and David Moore. 1992. "A Multilevel Analysis of Marital and Nonmarital Fertility in the U.S.” Social Forces 70(4):977-1011.

Bisin, Alberto, and Thierry Verdier. 2000. "Beyond the Melting Pot': Cultural Transmission, Marriage, and the Evolution of Ethnic and Religious Traits*." Quarterly Journal of Economics 115(3):955-88.

Bisin, Alberto, and Thierry Verdier. 2011. "The Economics of Cultural Transmission and Socialization.” Pp. 339-416 in Handbook of Social Economics, edited by J. Benhabib, M. Jackson, and A. Bisin. Amsterdam: Elsevier.

Bruce, Steve. 2011. Secularization: In Defence of an Unfashionable Theory. Oxford: Oxford University Press.

Buber-Ennser, Isabella, and Vegard Skirbekk. 2016. "Researchers, Religion and Childlessness." Journal of Biosocial Science 48(03):391-405.

Cutright, Phillips, Michael Hout, and David Johnson. 1976. "Structural Determinants of Fertility in Latin America: 1800-1970.” American Sociological Review 41(3):511-27.

Durkheim, Emile. 1912. The Elementary Forms of Religious Life. New York: Free Press.

Edgell, Penny, and Danielle Docka. 2007. "Beyond the Nuclear Family?” Sociological Forum 22(1):2550.

Esping-Andersen, Gøsta, and Francesco Billari. 2015. "Re-Theorizing Family Demographics." Population and Development Review 41(1):1-31.

Flor, Douglas, and Nancy Flanagan Knapp. 2001. "Transmission and Transaction: Predicting Adolescents' Internalization of Parental Religious Values.” Journal of Family Psychology 15(4):62745.

Freedman, Ronald, Pascal Whelpton, and John Smit. 1961. "Socio-Economic Factors in Religious Differentials in Fertility." American Sociological Review 26(4):608.

Gallagher, Sally. 2003. Evangelical Identity and Gendered Family Life. New Brunswick, NJ: Rutgers University Press.

Goldscheider, Frances, Eva Bernhardt, and Trude Lappegard. 2015. "The Gender Revolution: Understanding Changing Family and Demographic Behaviour." Population and Development Review 41(2):207-39.

Gorski, Philip, and Ateş Altınordu. 2008. “After Secularization?” Annual Review of Sociology 34(1):5585.

Hackett, Conrad. 2008. "Religion and Fertility in the United States." Princeton. 
Hackett, Conrad, Marcin Stonawski, Michaela Potančková, Brian Grim, and Vegard Skirbekk. 2015. "The Future Size of Religiously Affiliated and Unaffiliated Populations." Demographic Research 32(April):829-42.

Hauser, Robert. 1970. "Context and Consex: A Cautionary Tale." American Journal of Sociology 75(s4):645.

Hayford, Sarah, and Philip Morgan. 2008. "Religiosity and Fertility in the United States." Social Forces 86(3):1163-88.

Hout, Michael. 2016. "Saint Peter's Leaky Boat: Falling Intergenerational Persistence among U.S.Born Catholics since 1974." Sociology of Religion 77(1):1-17.

Hout, Michael, Andrew Greeley, and Melissa Wilde. 2001. "The Demographic Imperative in Religious Change in the United States.” American Journal of Sociology 107(2):468-500.

Hsu, Becky, Amy Reynolds, Conrad Hackett, and James Gibbon. 2008. "Estimating the Religious Composition of All Nations: An Empirical Assessment of the World Christian Database." Journal for the Scientific Study of Religion 47(4):678-93.

Hubert, Sandra. 2014. The Impact of Religiosity on Fertility: A Comparative Analysis of France, Hungary, Norway, and Germany. Springer.

Iannaccone, Laurence. 1998. "Introduction to the Economics of Religion." Journal of Economic Literature 36(3):1465-95.

De Jong, Gordon. 1965. "Religious Fundamentalism, Socio-Economic Status, and Fertility Attitudes in the Southern Appalachians." Demography 2(1):540-48.

van de Kaa, Dirk. 1987. "Europe's Second Demographic Transition.” Population Bulletin 42(1):1-57.

Kaufmann, Eric. 2010. Shall the Religious Inherit the Earth? Demography and Politics in the Twenty-First Century. London: Profile Books.

Kaufmann, Eric, Aanne Goujon, and Vegard Skirbekk. 2012. "The End of Secularization in Europe?” Sociology of Religion 73(1):69-91.

Kelley, Jonathan, and Nan Dirk De Graaf. 1997. "National Context, Parental Socialization, and Religious Belief." American Sociological Review 62(4):639-59.

Kohler, Hans-Peter, Francesco C. Billari, and José Antonio Ortega. 2002. "The Emergence of Lowest-Low Fertility in Europe During the 1990s." Population and Development Review 28(4):64180.

Kohler, Ulrich, Kristian Bernt Karlson, and Anders Holm. 2011. "Comparing Coefficients of Nested Nonlinear Probability Models.” Stata Journal 11(3):420-38.

Kravdal, Oystein. 2002. "Education and Fertility in Sub-Saharan Africa: Individual and Community Effects.” Demography 39(2):233-50.

Krull, Jennifer, and David MacKinnon. 2001. "Multilevel Modeling of Individual and Group Level Mediated Effects.” Multivariate Behavioral Research 36(2):249-77.

Lenski, Gerhard. 1961. The Religious Factor: A Sociological Study of Religion's Impact on Politics, Economics, and Family Life. Garden City, NY: Doubleday.

Lesthaeghe, Ron. 1983. "A Century of Demographic and Cultural Change in Western Europe." Population and Development Review 9(3):411-35.

Lesthaeghe, Ron. 2010. “The Unfolding Story of Transition.” Population and Development Review 36(2):211-51.

Lesthaeghe, Ron. 2014. "The Second Demographic Transition." Proceedings of the National Academy of Sciences 111(51):18112-15.

McDonald, Peter. 2000. "Gender Equity in Theories of Fertility Transition." Population and Development Review 26(3):427-39.

McDonald, Peter. 2013. "Societal Foundations for Explaining Low Fertility: Gender Equity." 
Demographic Research 28(May):981-94.

McQuillan, Kevin. 2004. "When Does Religion Influence Fertility?” Population and Development Review 30(1):25-56.

Montgomery, James. 2010. "Intergenerational Cultural Transmission as an Evolutionary Game." American Economic Journal: Microeconomics 2(4):115-36.

Myrskyla, Mikko, Joshua Goldstein, and Yen-hsin Alice Cheng. 2013. "New Cohort Fertility Forecasts for the Developed World." Population and Development Review 39(1):31-56.

Myrskyla, Mikko, Hans-Peter Kohler, and Francesco C. Billari. 2009. "Advances in Development Reverse Fertility Declines." Nature 460(August 6):741-43.

Norris, Pippa, and Ronald Inglehart. 2002. "Islamic Culture and Democracy: Testing the 'Clash of Civilizations' Thesis." Comparative Sociology 1(3):235-63.

Norris, Pippa, and Ronald Inglehart. 2011. Sacred and Secular: Religion and Politics Worldwide. 2nd ed. New York: Cambridge University Press.

Philipov, Dimiter, and Caroline Berghammer. 2007. "Religion and Fertility Ideals, Intentions and Behaviour: A Comparative Study of European Countries." Vienna Yearbook of Population Research 5(2007):271-305.

Scheitle, Christopher, Jennifer Kane, and Jennifer Van Hook. 2011. "Demographic Imperatives and Religious Markets: Considering the Individual and Interactive Roles of Fertility and Switching in Group Growth." Journal for the Scientific Study of Religion 50(3):470-82.

Schnabel, Landon. 2016a. "Gender and Homosexuality Attitudes across Religious Groups from the 1970s to 2014: Similarity, Distinction, and Adaptation.” Social Science Research 55(1):31-47.

Schnabel, Landon. 2016b. "Religion and Gender Equality Worldwide: A Country-Level Analysis." Social Indicators Research 129(2):893-907.

Schnabel, Landon, and Sean Bock. 2017. "The Persistent and Exceptional Intensity of American Religion: A Response to Recent Research.” Sociological Science 4:686-700.

Schnabel, Landon, and Sean Bock. 2018. "The Continuing Persistence of Intense Religion in the United States: Rejoinder.” Sociological Science 5:711-21.

Seguino, Stephanie. 2011. "Help or Hindrance? Religion's Impact on Gender Inequality in Attitudes and Outcomes." World Development 39(8):1308-21.

Sherkat, Darren, and John Wilson. 1995. "Preferences, Constraints, and Choices in Religious Markets.” Social Forces 73(3):993-1026.

Skirbekk, Vegard, Eric Kaufmann, and Anne Goujon. 2010. "Secularism, Fundamentalism, or Catholicism? The Religious Composition of the United States to 2043." Journal for the Scientific Study of Religion 49(2):293-310.

Stark, Rodney. 1996. The Rise of Christianity: A Sociologist Reconsiders History. Princeton, NJ: Princeton University Press.

Stark, Rodney. 2005. The Rise of Mormonism. New York: Columbia University Press.

Stephenson, Rob, Angela Baschieri, Steve Clements, Monique Hennink, and Nyovani Madise. 2007. "Contextual Influences on Modern Contraceptive Use in Sub-Saharan Africa." American Journal of Public Health 97(7):1233-40.

Stonawski, Marcin, Vegard Skirbekk, Conrad Hackett, Michaela Potančoková, Phillip Connor, and Brian Grim. 2015. “Global Population Projections by Religion: 2010-2050.” Pp. 99-116 in Yearbook of International Religious Demography, edited by B. Grim, T. Johnson, V. Skirbekk, and G. Zurlo. Boston, MA: Brill.

Thornton, Arland. 2001. "The Developmental Paradigm, Reading History Sideways, and Family Change." Demography 38(4):449-65.

Thornton, Arland, Georgina Binstock, Kathryn M. Yount, Mohammad Jalal Abbasi-Shavazi, Dirgha Ghimire, and Yu Xie. 2012. "International Fertility Change.” Demography 49(2):677-98. 
Voas, David, and Mark Chaves. 2016. "Is the United States a Counterexample to the Secularization Thesis?" American Journal of Sociology 121(5):1517-56.

Wilde, Melissa, and Sabrina Danielsen. 2015. "Fewer and Better Children: Race, Class, Religion, and Birth Control Reform in America." American Journal of Sociology 119(6):1710-60.

Young, Cristobal, and Katherine Holsteen. 2017. "Model Uncertainty and Robustness: A Computational Framework for Multimodel Analysis." Sociological Methods and Research 46(1):340.

Zaidi, Batool, and Philip Morgan. 2017. "The Second Demographic Transition Theory.” Annual Review of Sociology 43(1):473-92. 


\section{FIGURES AND TABLES}

Figure 1: Total Fertility Rate by Proportion Atheist or Agnostic, ARDA National Profiles
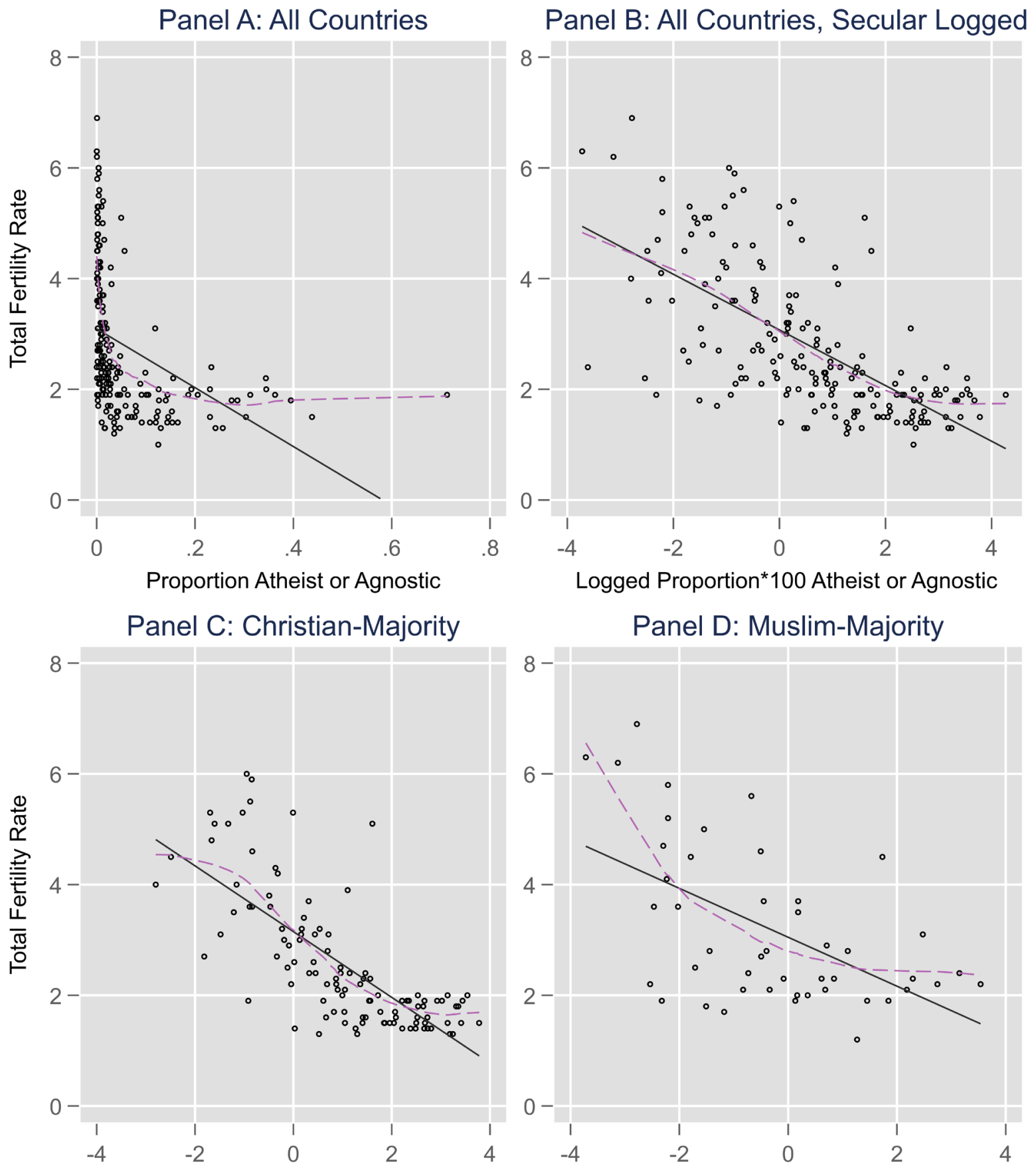

Logged Proportion*100 Atheist or Agnostic

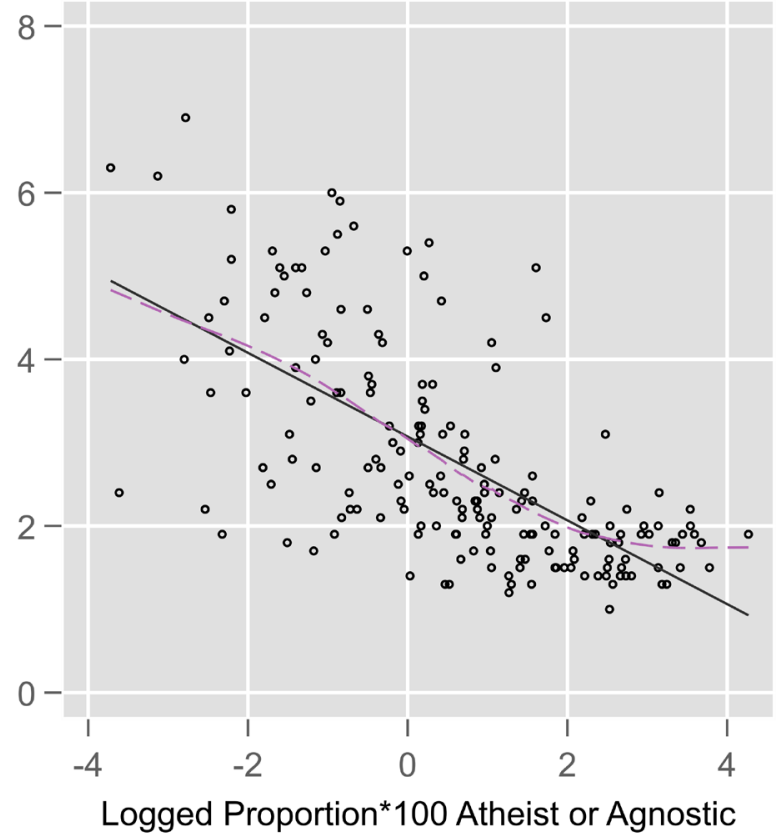

Panel D: Muslim-Majority

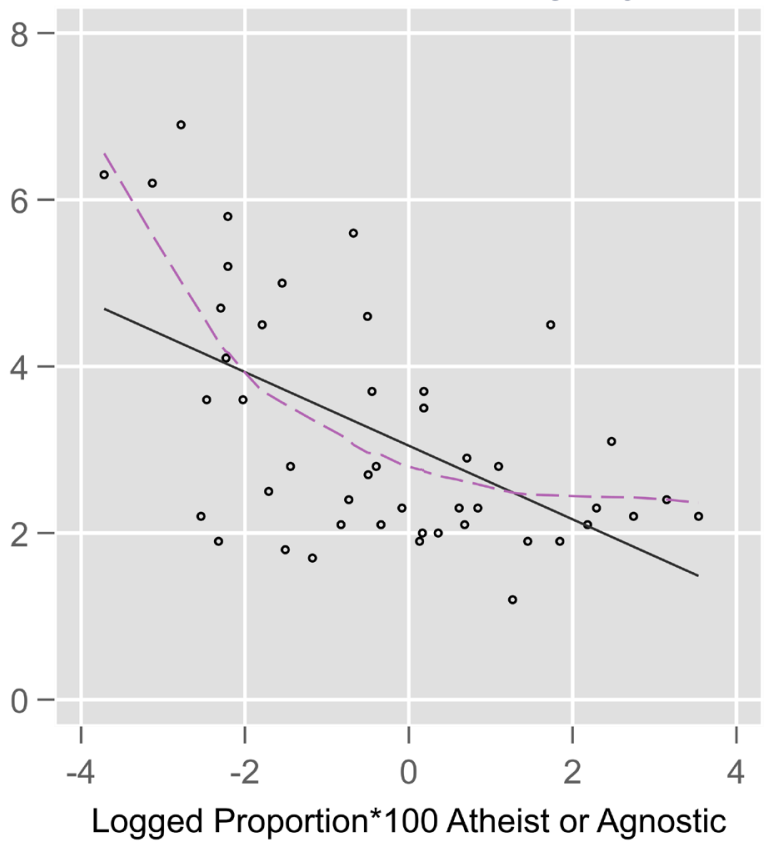

Source: ARDA National Profiles, 2011 Update ( $\mathrm{N}=181)$

Solid lines are linear predictions and dashed lines are lowess (locally weighted scatterplot smoothing) predictions

Note: Of the 181 total countries, 108 were majority Christian ( $>50 \%$ Christian) and 46 majority Muslim 
Figure 2: Children Ever Born by Four Secularism Measures, World Values Survey
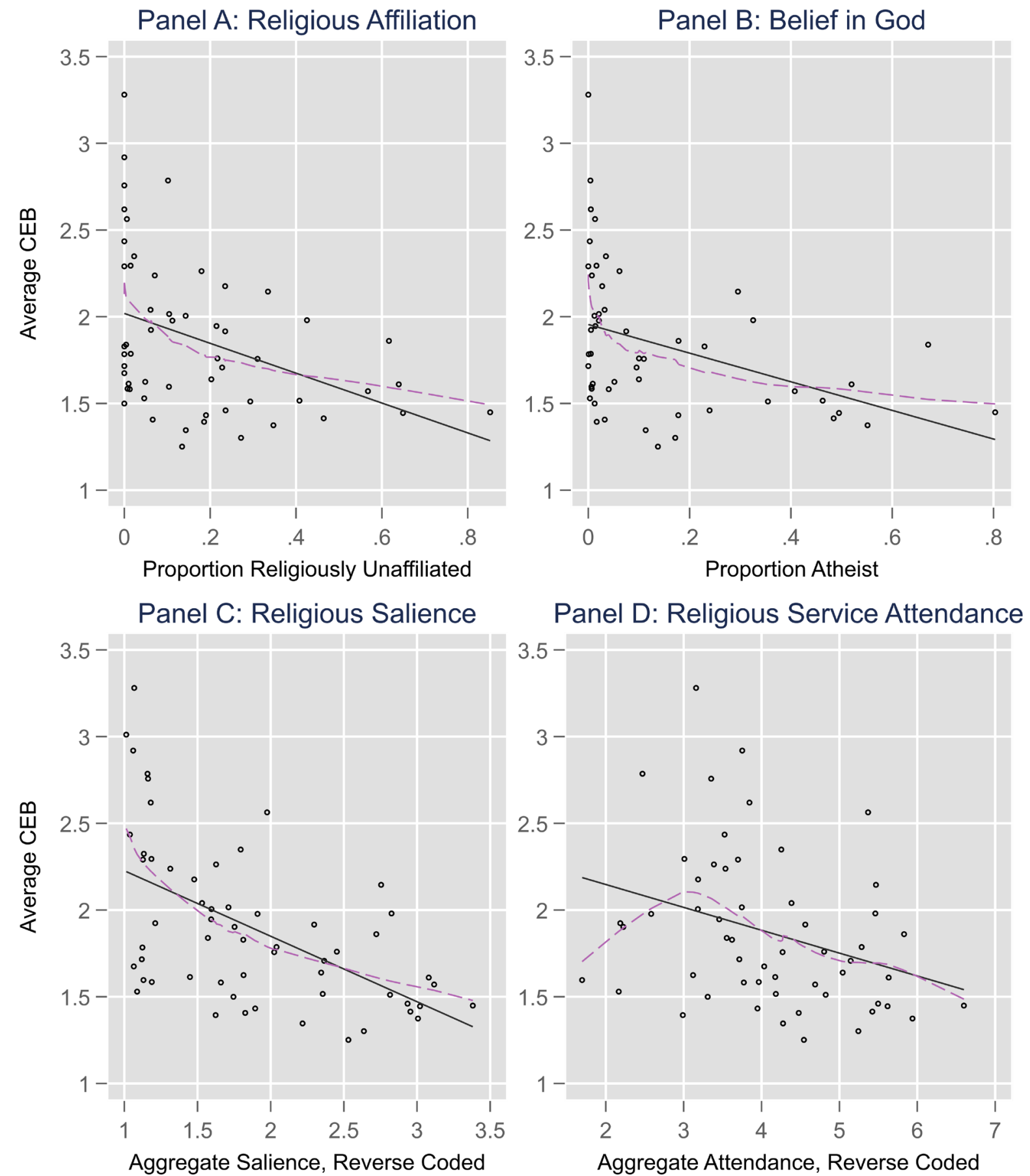

Source: World Values Survey, Wave 6 (2010-2014)

Solid lines are linear predictions and dashed lines are lowess (locally weighted scatterplot smoothing) predictions The 58 countries: Algeria, Azerbaijan, Argentina, Australia, Armenia, Bahrain, Brazil, Belarus, Chile, China, Taiwan, Colombia, Cyprus, Ecuador, Estonia, Georgia, Palestine, Germany, Ghana, India, Iraq, Japan, Kazakhstan, Jordan, South Korea, Kyrgyzstan, Kuwait, Lebanon, Libya, Malaysia, Mexico, Morocco, Netherlands, New Zealand, Nigeria, Pakistan, Peru, Philippines, Poland, Qatar, Romania, Russia, Rwanda, Singapore, Slovenia, South Africa, Zimbabwe, Spain, Sweden, Thailand, Trinidad and Tobago, Tunisia, Turkey, Ukraine, United States, Uruguay, Uzbekistan, and Yemen. 
Figure 3: Aggregate Children Ever Born by Aggregate Secularism Scale among Those 45 and Older, World Values Survey

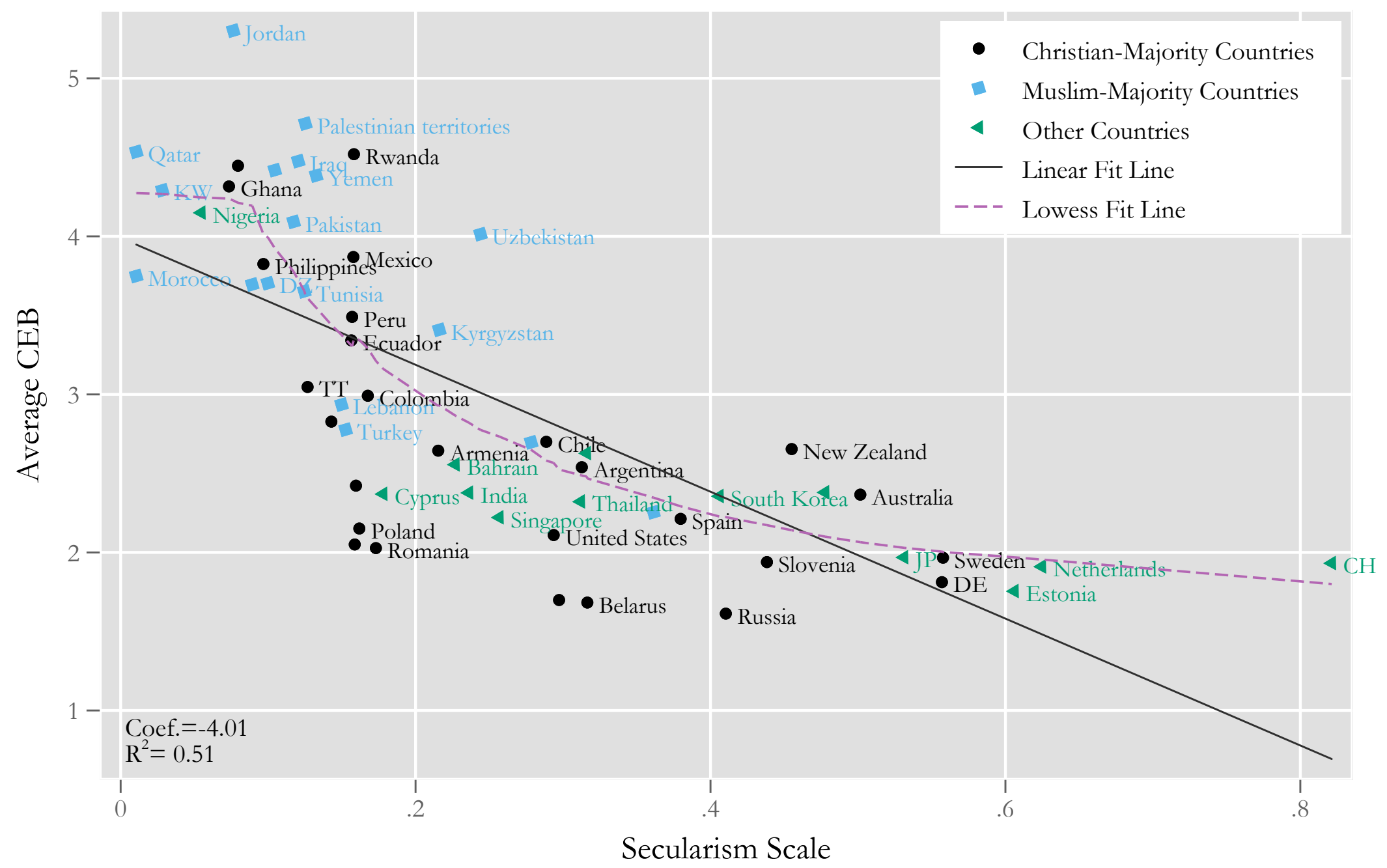


Figure 4: Model Robustness Results for a Range of Individual-Level and Country-Level Controls, World Values Survey

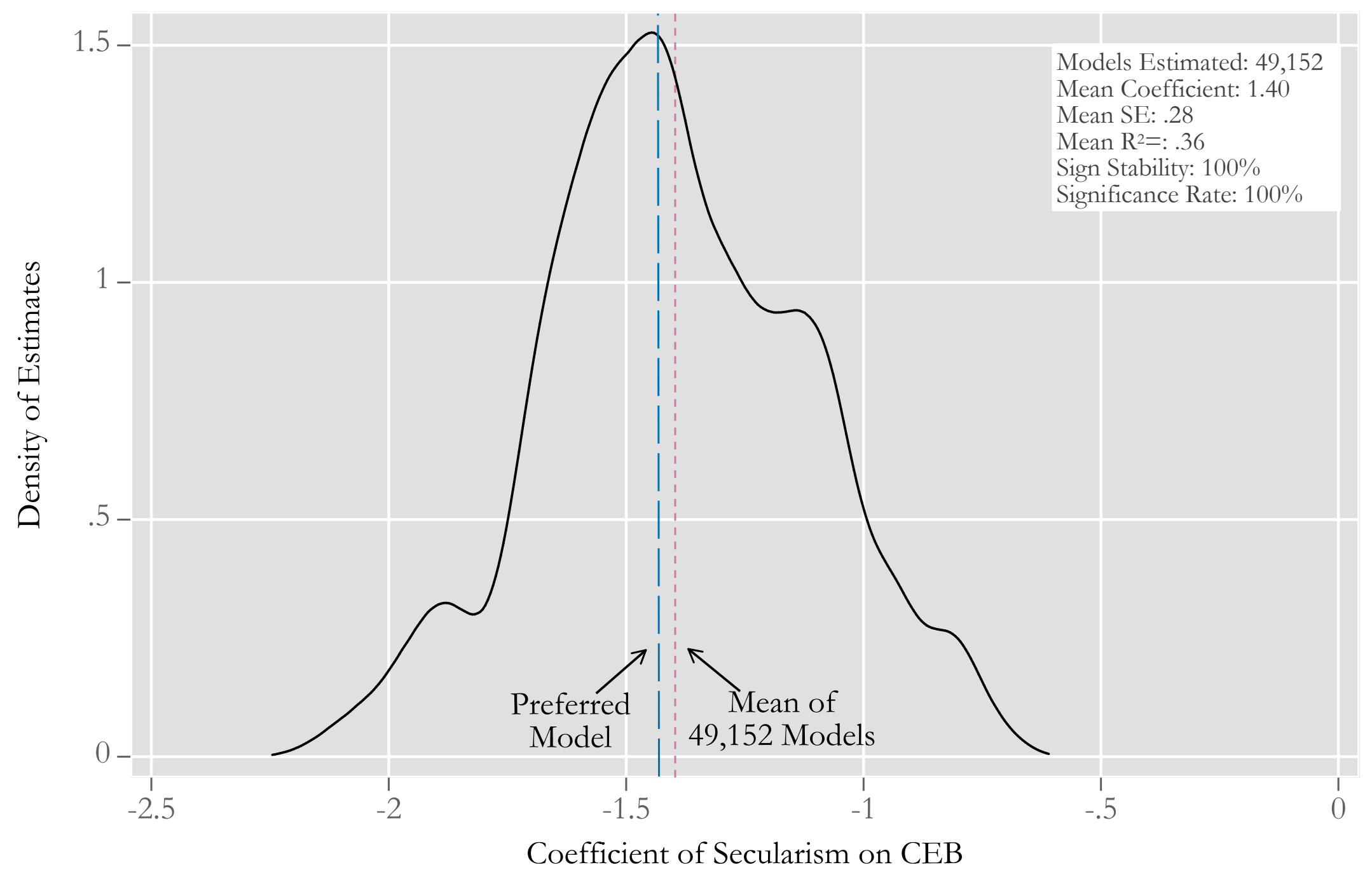


Figure 5: Predicted CEB by Country Secularism across Levels of Individual Secularism, World Values Survey

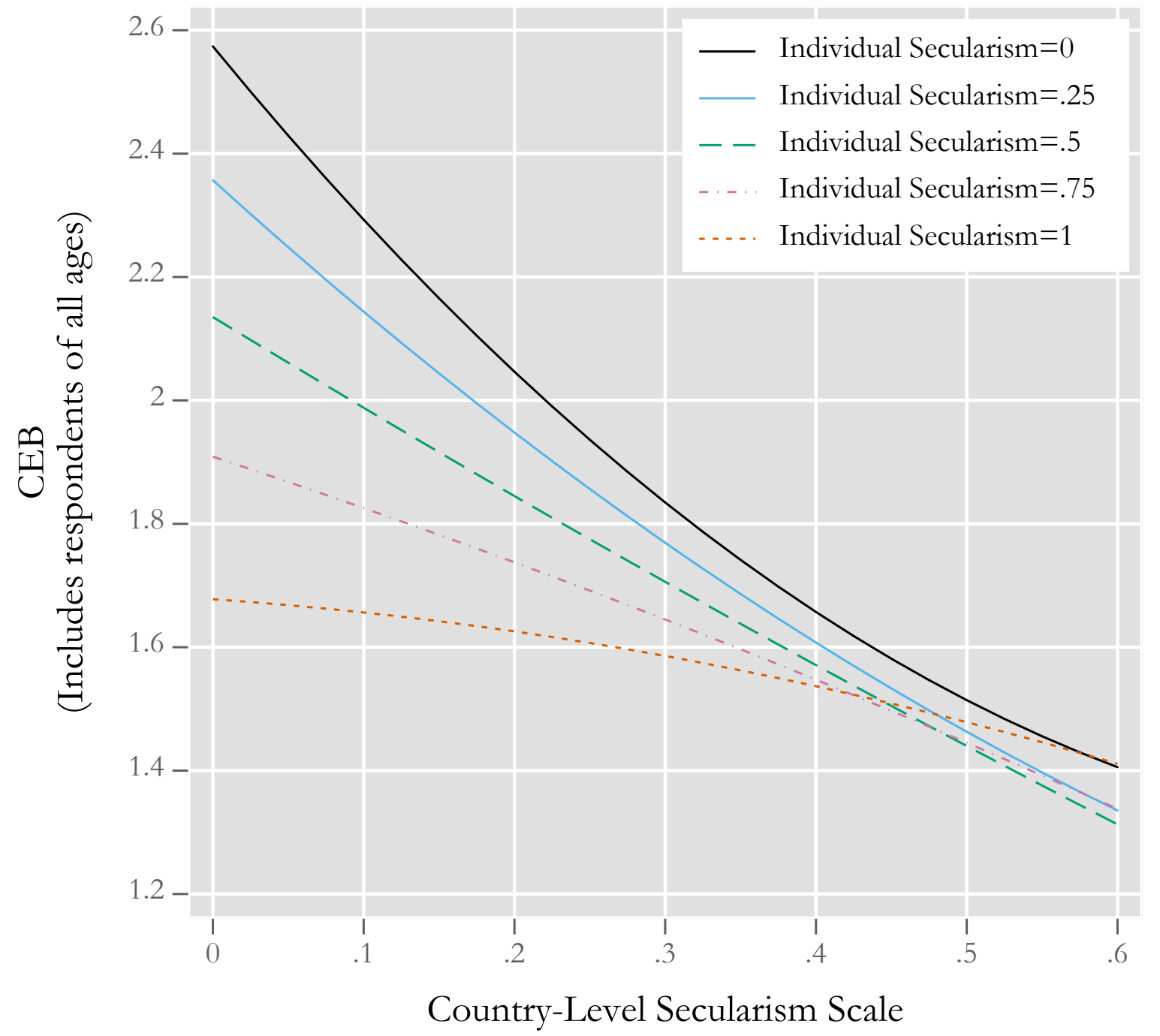

Note: Predictions control for both country-level (average education, per capita GDP, proportion urban, political system, and region) and individual-level factors (gender, relationship status, age, education, income, gender attitudes, abortion attitudes, and autonomy attitudes) in Model 2 of Table 2. Underlying model includes quadratics at country and individual level interacted with each other because there is a significant interaction for country*country*individual secularism. 
Table 1: OLS Regression of Total Fertility Rate on Proportion Agnostic or Atheist, ARDA National Profiles

\begin{tabular}{|c|c|c|c|c|}
\hline & Model 1 & Model 2 & Model 3 & Model 4 \\
\hline \multicolumn{5}{|l|}{ Secularism } \\
\hline Proportion Agnostic or Atheist & $\begin{array}{c}-5.32^{* * *} \\
(.91)\end{array}$ & & & \\
\hline Logged Proportion*100 Agnostic or Atheist & & $\begin{array}{l}-.50^{* * *} \\
(.04)\end{array}$ & $\begin{array}{l}-.17^{* * *} \\
(.04)\end{array}$ & $\begin{array}{l}-.11^{*} \\
(.05)\end{array}$ \\
\hline \multicolumn{5}{|l|}{ Potential Intermediary Factors } \\
\hline Gender Equity Index & & & & $\begin{array}{l}-.25 \\
(.76)\end{array}$ \\
\hline Modern Contraceptive Prevalence & & & & $\begin{array}{l}-.56 \\
(.38)\end{array}$ \\
\hline Abortion Policy & & & & $\begin{array}{l}-.13^{*} \\
(.06)\end{array}$ \\
\hline Controls & & & $\checkmark$ & $\checkmark$ \\
\hline Constant & 3.09 & 3.07 & 5.53 & 5.63 \\
\hline$N$ & 181 & 181 & 181 & 181 \\
\hline$R^{2}$ & .16 & .43 & .82 & .83 \\
\hline
\end{tabular}

Sources: ARDA National Profiles (2011 update of 2008 data), Social Watch (2008), UN Population Division (2010), Center for Reproductive Rights (2008), and KOF (2008).

Notes: Controls include education, logged per capita GDP, proportion urban, globalization, political system, and detailed UN regions. Freedom House political system classifications include democracy, restricted democratic practice, traditional monarchy, authoritarian regime, totalitarian regime, and protectorate (and I created a "missing" category with two countries in it: Hong Kong and Israeli Occupied Territories [Palestine]). Number of countries in 21 UN Regions present in the data range from 1 (Micronesia) to 18 (Western Asia). Micronesia is the only region with just one country in these data, though three regions include just two countries (Australia/New Zealand, Northern America, and Polynesia).

Standard errors in parentheses

${ }^{*} p<0.05,{ }^{* *} p<0.01,{ }^{* * *} p<0.001$ 
Table 2: Generalized Linear Mixed-Effects Multilevel Models with Country-Level Secularism Predicting Individual-Level Children Ever Born, World Values Survey

\begin{tabular}{|c|c|c|c|c|c|}
\hline & Model 1 & Model 2 & Model 3 & Model 4 & Model 5 \\
\hline Secularism (Country-Level) & $\begin{array}{c}-1.88^{* * *} \\
(.28)\end{array}$ & $\begin{array}{l}-1.43^{* * *} \\
(0.25)\end{array}$ & $\begin{array}{c}-1.13^{* * *} \\
(.31)\end{array}$ & $\begin{array}{l}-81^{* *} \\
(.30)\end{array}$ & $\begin{array}{l}-.45 \\
(.30)\end{array}$ \\
\hline \multicolumn{6}{|l|}{ Potential Intermediary Factors } \\
\hline Gender Equity Index & & & $\begin{array}{l}-3.87 \\
(2.13)\end{array}$ & $\begin{array}{l}-4.11 \\
(2.11)\end{array}$ & $\begin{array}{l}-2.44 \\
(2.03)\end{array}$ \\
\hline Gender Equity Index Squared & & & $\begin{array}{r}3.64^{*} \\
(1.83)\end{array}$ & $\begin{array}{c}4.41^{*} \\
(1.81)\end{array}$ & $\begin{array}{c}2.88 \\
(1.75)\end{array}$ \\
\hline Modern Contraceptive Prevalence & & & $\begin{array}{l}-.52^{*} \\
(.25)\end{array}$ & $\begin{array}{l}-.05 \\
(.25)\end{array}$ & $\begin{array}{l}-.06 \\
(.23)\end{array}$ \\
\hline Abortion Policy & & & $\begin{array}{l}-.01 \\
(.04)\end{array}$ & $\begin{array}{l}-.04 \\
(.03)\end{array}$ & $\begin{array}{l}-.03 \\
(.03)\end{array}$ \\
\hline Values: Gender & & & & $\begin{array}{c}-2.18^{* * *} \\
(.58)\end{array}$ & $\begin{array}{c}-2.11^{* * *} \\
(.53)\end{array}$ \\
\hline Values: Abortion & & & & $\begin{array}{l}-.04 \\
(.41)\end{array}$ & $\begin{array}{c}.51 \\
(.42)\end{array}$ \\
\hline Values: Autonomy & & & & & $\begin{array}{c}-1.58^{* *} \\
(.51)\end{array}$ \\
\hline \multicolumn{6}{|l|}{ Individual-Level Controls } \\
\hline Secularism (Individual-Level) & $\begin{array}{l}-.17^{* * *} \\
(.02)\end{array}$ & $\begin{array}{l}-.17^{* * *} \\
(.02)\end{array}$ & $\begin{array}{l}-.17^{* * *} \\
(.02)\end{array}$ & $\begin{array}{l}-.17^{* * *} \\
(.02)\end{array}$ & $\begin{array}{l}-.17^{* * *} \\
(.02)\end{array}$ \\
\hline Other Individual-Level Controls ${ }^{a}$ & $\checkmark$ & $\checkmark$ & $\checkmark$ & $\checkmark$ & $\checkmark$ \\
\hline Country-Level Controls ${ }^{b}$ & & $\checkmark$ & $\checkmark$ & $\checkmark$ & $\checkmark$ \\
\hline Constant & 2.42 & 1.85 & 2.67 & 3.87 & 3.66 \\
\hline Individual-level $N$ & 83,301 & 83,301 & 83,301 & 83,301 & 83,301 \\
\hline Country-level N & 58 & 58 & 58 & 58 & 58 \\
\hline Within $R^{2}$ & .39 & .39 & .39 & .39 & .39 \\
\hline Between $R^{2}$ & .31 & .70 & .75 & .80 & .83 \\
\hline Overall $R^{2}$ & .39 & .41 & .41 & .42 & .42 \\
\hline
\end{tabular}

Sources: World Values Survey, Wave 6 (2010-2014), Social Watch (2012), UN Population Division (2010), and Center for Reproductive Rights (2013)

${ }^{a}$ Other individual-level controls include gender, relationship status, age, education, income, gender attitudes, abortion attitudes, and autonomy attitudes.

${ }^{\mathrm{b}}$ Country-level controls include education, logged per capita GDP, proportion urban, political system, and region. Standard errors in parentheses; ${ }^{*} p<0.05,{ }^{* *} p<0.01,{ }^{* * *} p<0.001$ 


\section{SUPPLEMENTAL MATERIALS FOR “SECULARISM AND FERTILITY WORLDWIDE}

\section{Figure S1: Total Fertility Rate by Proportion Unaffiliated, ARDA and Pew}
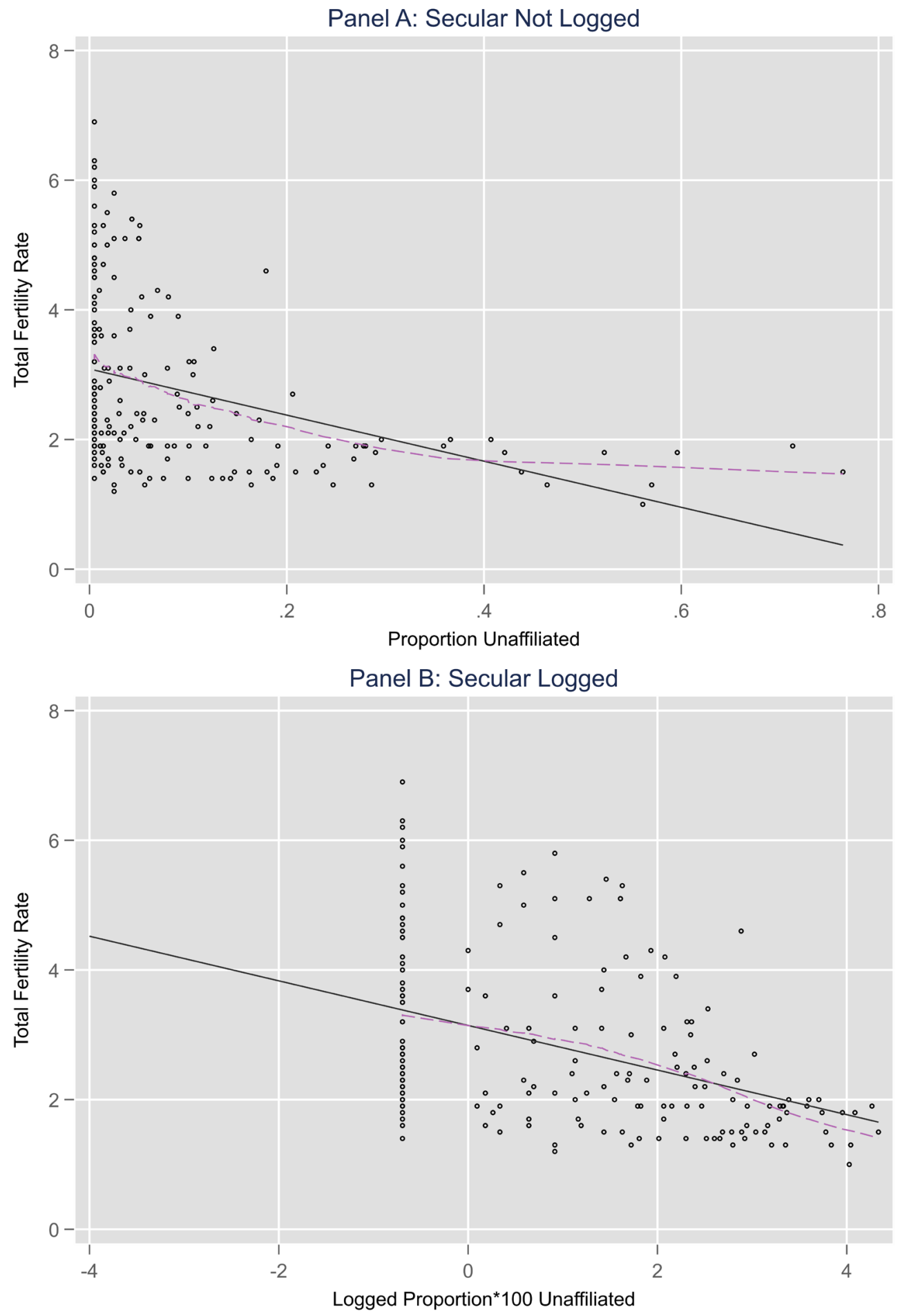

Sources: ARDA National Profiles, 2011 Update (TFR) and Pew Research Center 2010 Religious Composition Estimates (proportion unaffiliated) $(\mathrm{N}=181)$

Solid lines are linear predictions and dashed lines are lowess (locally weighted scatterplot smoothing) prediction.

Note: Pew did not provide specific estimates for countries with less than $1 \%$ unaffiliated and simply indicated that less than $1 \%$ of the population was unaffiliated. These countries have all been set to .5\% unaffiliated here. 
Figure S2: Aggregate Children Ever Born by Aggregate Secularism Scale, World Values Survey

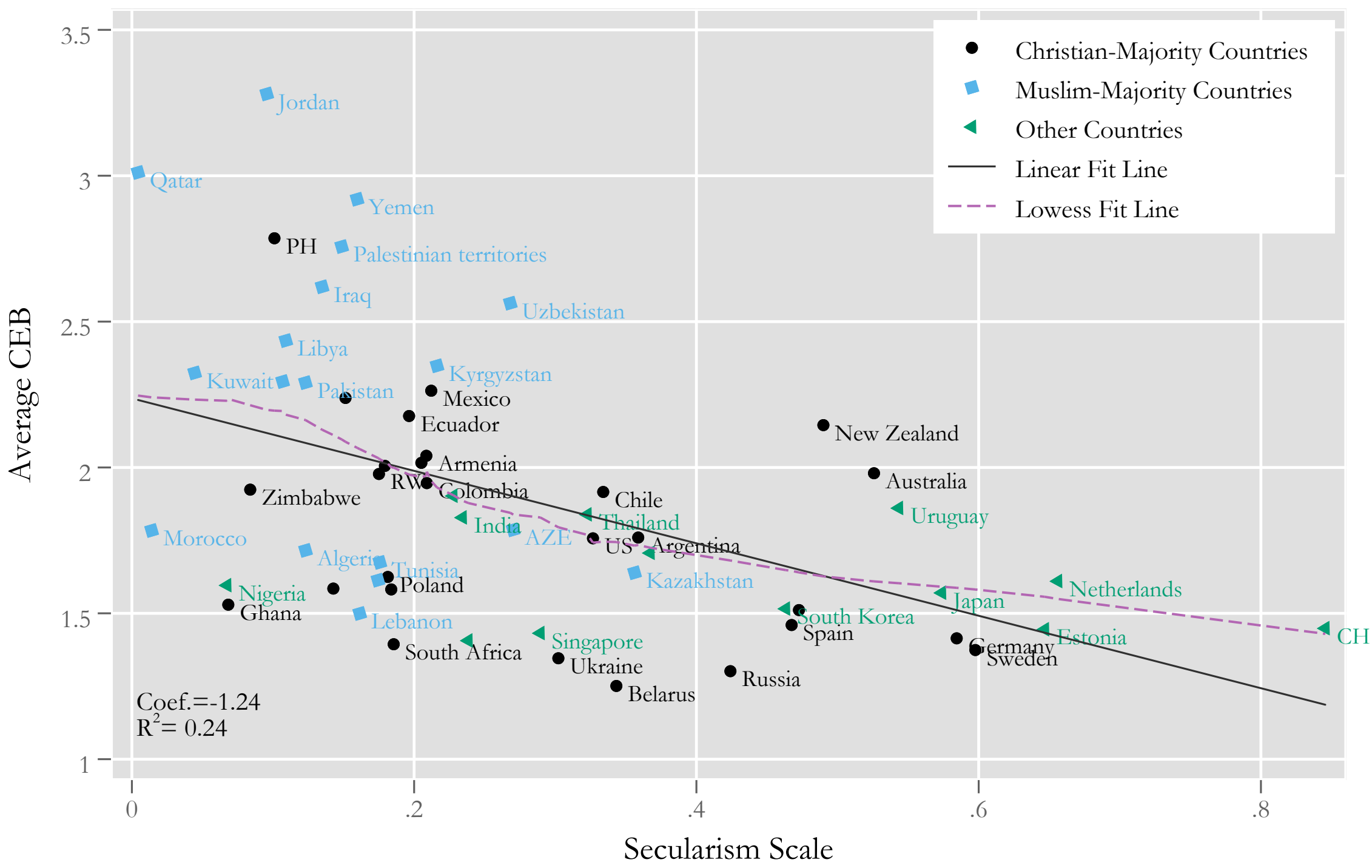


Figure S3: Estimated CEB Difference by Secularism as Measured by Proportion Unaffiliated across Waves 1 to 6 of the World Values Survey

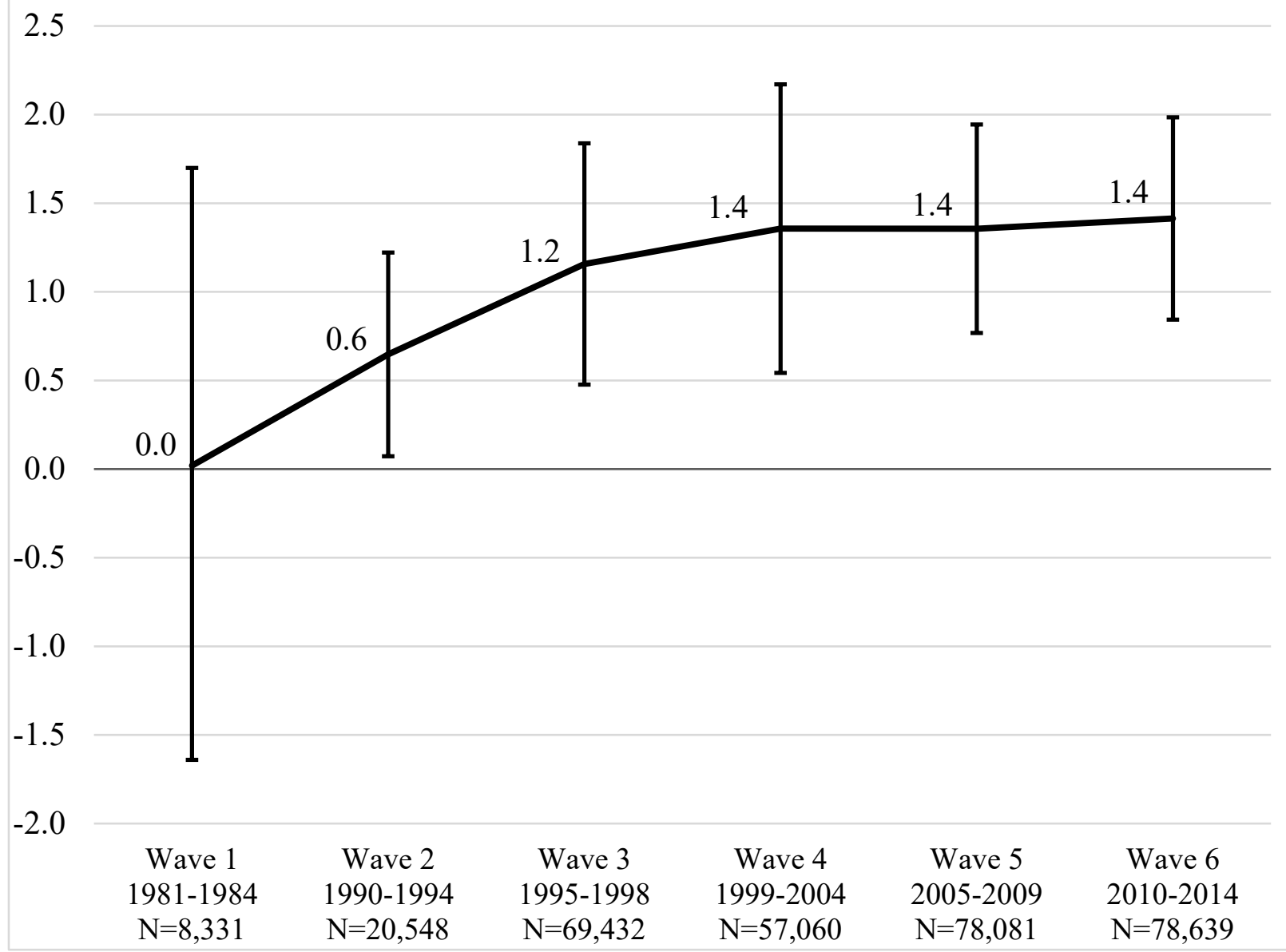

Source: World Values Survey Waves 1 to $6(\mathrm{~N}=312,091)$

Note: Error bars indicate 95\% confidence intervals. Estimates based on models with proportion unaffiliated as the measure of country-level secularism and individual-level controls for religious affiliation, relationship status, age, education, and income. 
Figure S4: Predicted Secularism by Age within and across Countries, World Values Survey

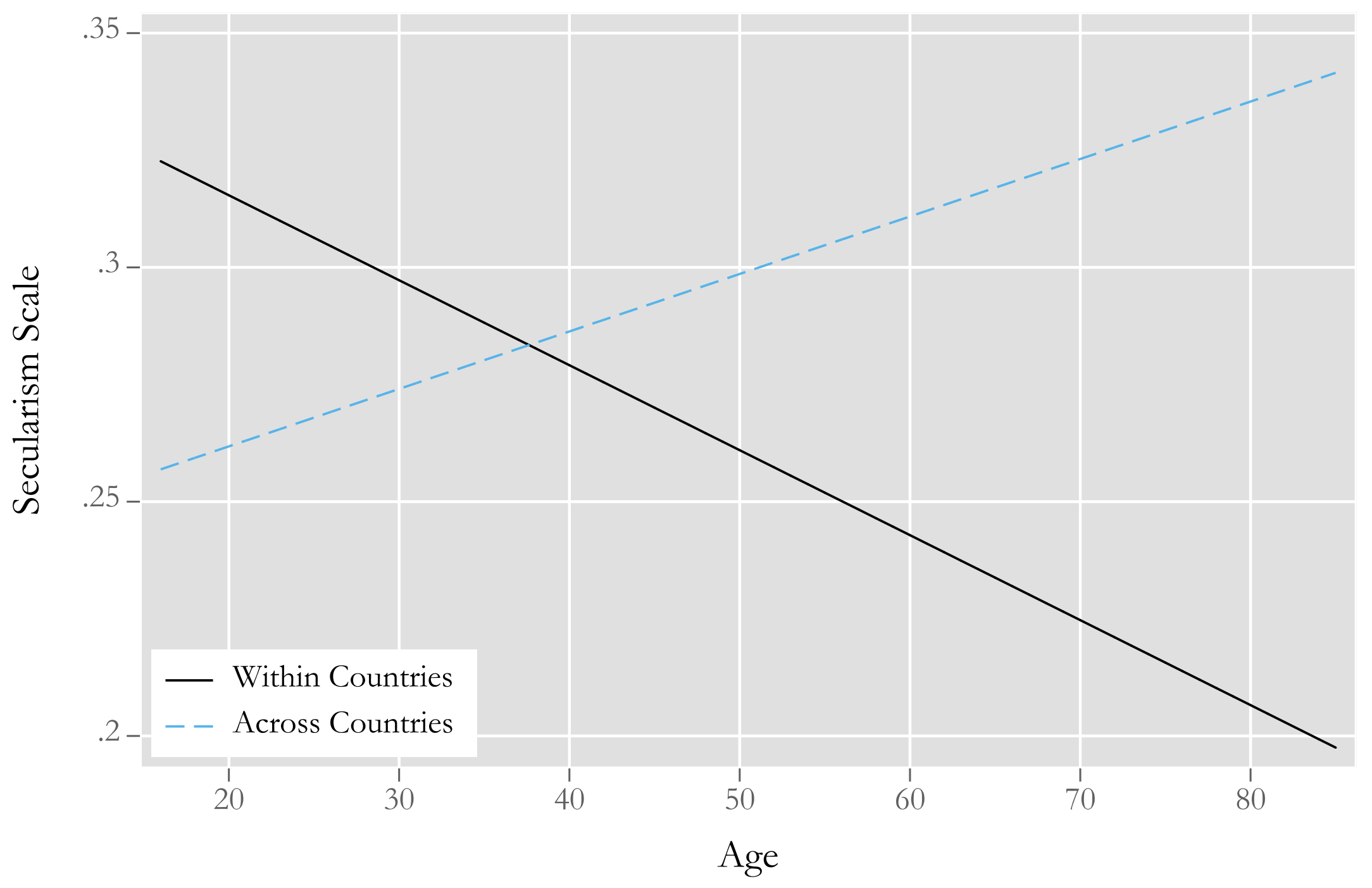


Figure S5: Aggregate Age by Aggregate Secularism Scale, World Values Survey

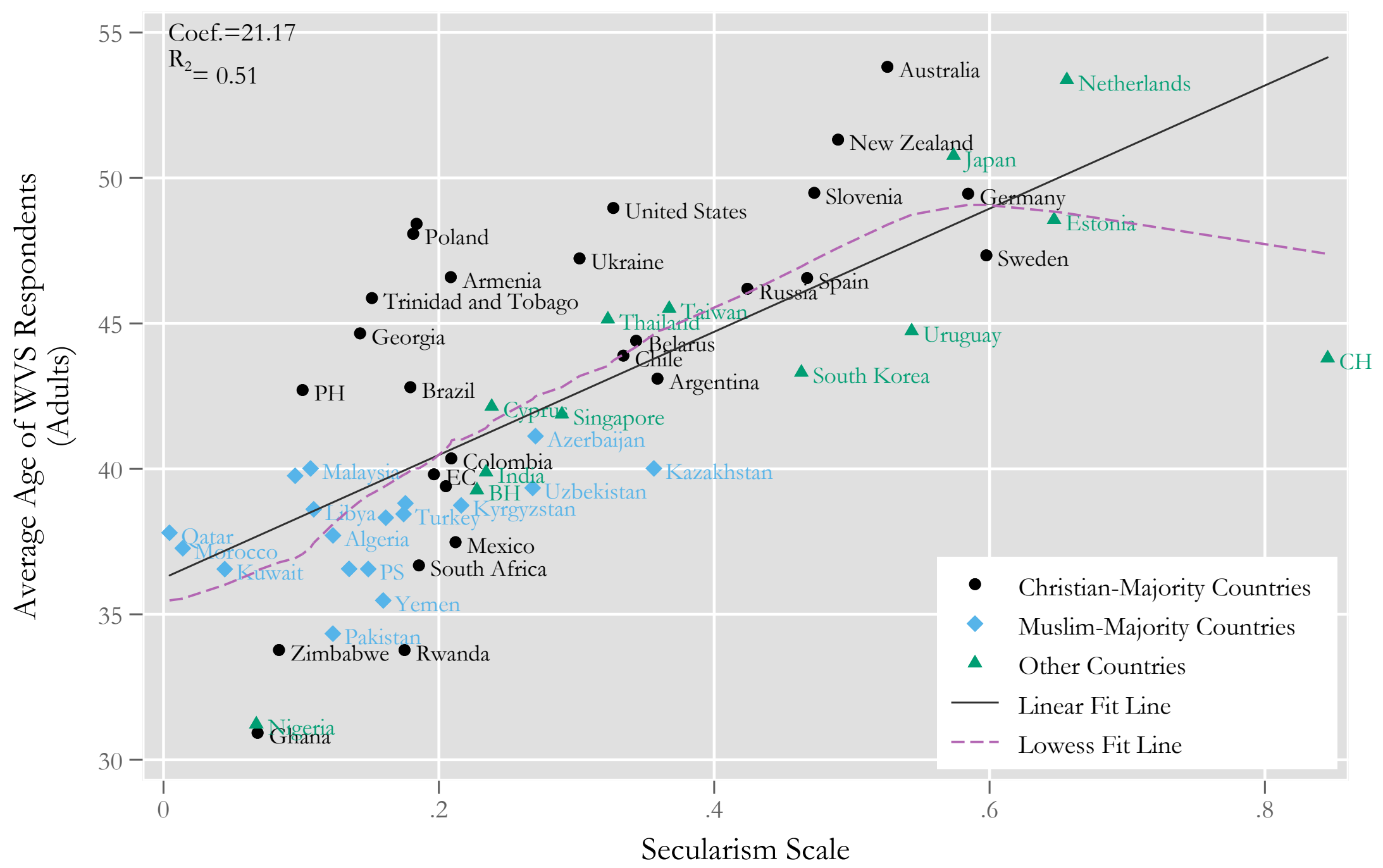


Supplemental Materials for Secularism and Fertility Worldwide 6

Table S1: Descriptive Statistics for ARDA National Profiles and World Values Survey

\begin{tabular}{|c|c|c|c|c|}
\hline Measures & Metric & Mean & SD & Range \\
\hline \multicolumn{5}{|l|}{ Country-Level Analyses (ARDA) } \\
\hline \multicolumn{5}{|l|}{ Dependent Variable } \\
\hline Total Fertility Rate (TFR) & Number of live births per woman & 2.77 & 1.31 & $1-6.9$ \\
\hline \multicolumn{5}{|l|}{ Key Independent Variable } \\
\hline Proportion Agnostic or Atheist & Proportion of population agnostic or atheist & .06 & .10 & $.00-.71$ \\
\hline \multicolumn{5}{|l|}{ Covariates } \\
\hline Education & Primary enrollment proportion & .87 & .13 & .32-1 \\
\hline Per Capita GDP (PPP) & In thousands of U.S. dollars & 13.05 & 14.51 & $.18-79.43$ \\
\hline Proportion Urban & Proportion of population living in urban areas & .55 & .23 & $.10-1$ \\
\hline Globalization Index & Not at all globalized $=0$ to fully globalized $=1$ & .58 & .17 & $.23-.93$ \\
\hline Political System & Freedom House political system categories & & & \\
\hline Region & Categories for UN regions & & & \\
\hline Gender Equity Index & Not at all equitable $=0$ to fully equitable $=1$ & .61 & .12 & $.29-.89$ \\
\hline Modern Contraceptive Prevalence & No women using $=0$ to all women using $=1$ & .42 & .23 & $.01-.84$ \\
\hline Abortion Policy & Prohibited $/$ mother's life $=1$ to any reason $=4$ & 2.16 & 1.34 & $1-4$ \\
\hline \multicolumn{5}{|l|}{ Multilevel Analyses (WVS) } \\
\hline \multicolumn{5}{|l|}{ Dependent Variable } \\
\hline Children Ever Born (CEB) & Number of children had by respondent & 1.85 & 1.79 & $0-8$ \\
\hline \multicolumn{5}{|l|}{ Key Independent Variable } \\
\hline Secularism Scale & $\begin{array}{l}\text { Summative scale }(a=.93 \text { - wholly religious }=0 \text { to } \\
\text { wholly secular }=1) \text { of proportion unaffiliated, } \\
\text { proportion atheist, aggregate religious service } \\
\text { attendance, and aggregate religious salience }\end{array}$ & .29 & .19 & $.00-.85$ \\
\hline \multicolumn{5}{|l|}{ Individual-Level Covariates } \\
\hline Secularism Scale & $\begin{array}{l}\text { Individual-level summative scale of the items in } \\
\text { the country-level secularism scale }(a=.79)\end{array}$ & .29 & .29 & $0-1$ \\
\hline Woman & Woman $=1$ & .52 & & \\
\hline Married or Cohabitating & Married or cohabiting $=1$, all else $=0$ & .62 & & \\
\hline Age & In years & 42.08 & 16.59 & $16-99$ \\
\hline Education & $\begin{array}{l}\text { No formal education }=1 \text { to university-level with } \\
\text { degree }=9\end{array}$ & 5.76 & 2.38 & $1-9$ \\
\hline Income & $\begin{array}{l}\text { Self-positioning on a scale of relative incomes } \\
\text { from first step }=1 \text { to tenth step }=10\end{array}$ & 4.90 & 2.11 & $1-10$ \\
\hline Gender Attitudes Scale & Unequal $=0$ to equal $=1$ & .55 & .28 & $0-1$ \\
\hline Abortion Attitudes Scale & Oppose $=0$ to support $=1$ & .26 & .31 & $0-1$ \\
\hline Autonomy Attitudes Scale & Oppose $=0$ to support $=1$ & .43 & .23 & $0-1$ \\
\hline \multicolumn{5}{|l|}{ Country-Level Covariates } \\
\hline Country's Average Education & Mean education of country's respondents & 5.76 & 1.01 & $2.66-7.77$ \\
\hline Per Capita GDP (PPP) & In thousands of U.S. dollars & 17.39 & 19.09 & $.67-79.43$ \\
\hline Proportion Urban & Proportion of population living in urban areas & .67 & .20 & $.09-1$ \\
\hline Political System & Freedom House political system categories & & & \\
\hline Region & Categories for continents & & & \\
\hline Country’s Gender Equity Index & Not at all equitable $=0$ to fully equitable $=1$ & .65 & 13 & $.24-.87$ \\
\hline Modern Contraceptive Prevalence & No women using $=0$ to all women using $=1$ & .51 & .19 & $.08-.84$ \\
\hline Country's Abortion Policy & Prohibited $/$ mother's life $=1$ to any reason $=4$ & 2.68 & 1.38 & $1-4$ \\
\hline Gender Attitudes & Mean, unequal $=0$ to equal $=1$ & .55 & 14 & $.30-.86$ \\
\hline Abortion Attitudes & Mean, oppose $=0$ to support abortion=1 & .26 & 15 & $.06-.78$ \\
\hline Autonomy Attitudes & Mean, oppose $=0$ to support autonomy $=1$ & .43 & .11 & $.20-.65$ \\
\hline
\end{tabular}

Sources: ARDA National Profiles (2011 Update of 2008 Data; N=181), Wave 6 (2010-2014) of the World Values Survey

$(\mathrm{N}=83,301)$, and additional country-level data from Social Watch (2008 and 2012 to supplement ARDA and WVS), Center for

Reproductive Rights (2008 and 2013 to supplement ARDA and WVS), KOF (2008 and 2012 to supplement ARDA and WVS), United Nations (2010 and 2010-2015 to supplement ARDA and WVS), and World Bank (2012 to supplement WVS) 
Table S2: Correlation Matrix, ARDA National Profiles

\begin{tabular}{|c|c|c|c|c|c|c|c|c|c|}
\hline & $(1)$ & $(2)$ & (3) & (4) & $(5)$ & $(6)$ & $(7)$ & $(8)$ & $(9)$ \\
\hline (1) Total Fertility Rate & 1 & & & & & & & & \\
\hline (2) Proportion Agnostic or Atheist & $-.40^{*}$ & 1 & & & & & & & \\
\hline (3) Logged*100 Proportion Agnostic or Atheist & $-.66^{*}$ & $.75^{*}$ & 1 & & & & & & \\
\hline (4) Education & $-.61^{*}$ & $.26^{*}$ & $.36^{*}$ & 1 & & & & & \\
\hline (5) Logged Per Capita GDP (PPP) & $-.75^{*}$ & $.39^{*}$ & $.58^{*}$ & $.54^{*}$ & 1 & & & & \\
\hline (6) Proportion Urban & $-.57^{*}$ & $.31^{*}$ & $.54^{*}$ & $.33^{*}$ & $.73^{*}$ & 1 & & & \\
\hline (7) Globalization Index & $-.66^{*}$ & $.44^{*}$ & $.61^{*}$ & $.51^{*}$ & $.79^{*}$ & $.66^{*}$ & 1 & & \\
\hline (8) Gender Equity & $-.57^{*}$ & $.50^{*}$ & $.60^{*}$ & $.54^{*}$ & $.54^{*}$ & $.37^{*}$ & $.61^{*}$ & 1 & \\
\hline (9) Modern Contraceptive Prevalence & $-.69^{*}$ & $.46^{*}$ & $.55^{*}$ & $.62^{*}$ & $.62^{*}$ & $.50^{*}$ & $.60^{*}$ & $.61^{*}$ & 1 \\
\hline (10) Abortion Policy & $-.55^{*}$ & $.55^{*}$ & $.64^{*}$ & $.34^{*}$ & $.40^{*}$ & .23 & $.50^{*}$ & $.47^{*}$ & $.32^{*}$ \\
\hline
\end{tabular}

Social Watch (2008), Center for Reproductive Rights (2008), and KOF (2008)

${ }^{*} p<0.001$ (two-tailed) 
Table S3: Correlation Matrix, World Values Survey

\begin{tabular}{|c|c|c|c|c|c|c|c|c|c|c|c|c|c|c|c|c|c|c|c|}
\hline & (1) & (2) & (3) & (4) & (5) & (6) & (7) & (8) & (9) & $(10)$ & $(11)$ & $(12)$ & (13) & (14) & (15) & (16) & $(17)$ & (18) & (19) \\
\hline (1) Children Ever Born & 1 & & & & & & & & & & & & & & & & & & \\
\hline (2) Secularism (Country-Level) & $-.12^{*}$ & 1 & & & & & & & & & & & & & & & & & \\
\hline (3) Secularism (Individual-Level) & $-.16^{*}$ & $.67^{*}$ & 1 & & & & & & & & & & & & & & & & \\
\hline (4) Woman & $.07^{*}$ & $.02^{*}$ & $-.05^{*}$ & 1 & & & & & & & & & & & & & & & \\
\hline (5) Married & $.41^{*}$ & $.05^{*}$ & -.01 & $-.02^{*}$ & 1 & & & & & & & & & & & & & & \\
\hline (6) Age & $.46^{*}$ & $.24^{*}$ & $.07^{*}$ & $.03^{*}$ & $.22^{*}$ & 1 & & & & & & & & & & & & & \\
\hline (7) Education & $-.27^{*}$ & $.13^{*}$ & $.12^{*}$ & $-.04^{*}$ & $-.07^{*}$ & $-.18^{*}$ & 1 & & & & & & & & & & & & \\
\hline (8) Income & $-.08^{*}$ & $-.08^{*}$ & $-.04^{*}$ & $-.03^{*}$ & $.03^{*}$ & $-.12^{*}$ & $.24^{*}$ & 1 & & & & & & & & & & & \\
\hline (9) Gender Attitudes & $-.12^{*}$ & $.28^{*}$ & $.22^{*}$ & $.17^{*}$ & $-.05^{*}$ & $.04^{*}$ & $.16^{*}$ & .01 & 1 & & & & & & & & & & \\
\hline (10) Abortion Attitudes & $-.12^{*}$ & $.35^{*}$ & $.36^{*}$ & $.01^{*}$ & $-.02^{*}$ & $.05^{*}$ & $.15^{*}$ & $.03^{*}$ & $.21^{*}$ & 1 & & & & & & & & & \\
\hline (11) Autonomy Attitudes & $-.15^{*}$ & $.36^{*}$ & .36 & $-.02^{*}$ & $-.02^{*}$ & .00 & $.20^{*}$ & $.06^{*}$ & $.16^{*}$ & $.27^{*}$ & 1 & & & & & & & & \\
\hline (12) Country's Average Education & $-.06^{*}$ & $.30^{*}$ & $.20^{*}$ & $.03^{*}$ & $.01^{*}$ & $.16^{*}$ & $.43^{*}$ & $.05^{*}$ & $.13^{*}$ & $.20^{*}$ & $.21^{*}$ & 1 & & & & & & & \\
\hline (13) Logged Per Capita GDP (PPP) & $-.03^{*}$ & $.39^{*}$ & $.26^{*}$ & .00 & $.02^{*}$ & $.18^{*}$ & $.18^{*}$ & $.07^{*}$ & $.22^{*}$ & $.29^{*}$ & $.19^{*}$ & $.43^{*}$ & 1 & & & & & & \\
\hline (14) Country Proportion Urban & $-.03^{*}$ & $.25^{*}$ & $.17^{*}$ & .00 & $-.03^{*}$ & $.12^{*}$ & $.16^{*}$ & $.03^{*}$ & $.16^{*}$ & $.16^{*}$ & $.10^{*}$ & $.37^{*}$ & $.64^{*}$ & 1 & & & & & \\
\hline (15) Country's Gender Equity Index & $-.09^{*}$ & $.42^{*}$ & $.28^{*}$ & $.04^{*}$ & $-.04^{*}$ & $.17^{*}$ & $.21^{*}$ & -.01 & $.36^{*}$ & $.26^{*}$ & $.18^{*}$ & $.48^{*}$ & $.33^{*}$ & $.21^{*}$ & 1 & & & & \\
\hline (16) Modern Contraceptive Prevalence & $-.08^{*}$ & $.61^{*}$ & $.41^{*}$ & $.02^{*}$ & $.01^{*}$ & $.16^{*}$ & $.08^{*}$ & $-.07^{*}$ & $.33^{*}$ & $.24^{*}$ & $.22^{*}$ & $.18^{*}$ & $.26^{*}$ & $.27^{*}$ & $.43^{*}$ & 1 & & & \\
\hline (17) Country’s Abortion Policy & $-.15^{*}$ & $.56^{*}$ & $.37^{*}$ & $.03^{*}$ & .00 & $.17^{*}$ & $.17^{*}$ & -.01 & $.14^{*}$ & $.27^{*}$ & $.28^{*}$ & $.40^{*}$ & $.25^{*}$ & $.06^{*}$ & $.39^{*}$ & $.34^{*}$ & 1 & & \\
\hline (18) Country’s Gender Attitudes & $-.11^{*}$ & $.54^{*}$ & $.36^{*}$ & $.03^{*}$ & $-.03^{*}$ & $.21^{*}$ & $.11^{*}$ & $-.07^{*}$ & $.51^{*}$ & $.32^{*}$ & $.21^{*}$ & $.26^{*}$ & $.42^{*}$ & $.31^{*}$ & $.70^{*}$ & $.65^{*}$ & $.28^{*}$ & 1 & \\
\hline (19) Country’s Abortion Attitudes & $-.12^{*}$ & $.70^{*}$ & $.47^{*}$ & $.02^{*}$ & .00 & $.24^{*}$ & $.17^{*}$ & $-.04^{*}$ & $.33^{*}$ & $.50^{*}$ & $.34^{*}$ & $.40^{*}$ & $.58^{*}$ & $.33^{*}$ & $.52^{*}$ & $.48^{*}$ & $.54^{*}$ & $.64^{*}$ & 1 \\
\hline (20) Country's Autonomy Attitudes & $-.14^{*}$ & $.78^{*}$ & $.53^{*}$ & $.02^{*}$ & $.04^{*}$ & $.23^{*}$ & $.19^{*}$ & $-.02^{*}$ & $.23^{*}$ & $.37^{*}$ & $.46^{*}$ & $.44^{*}$ & $.41^{*}$ & $.22^{*}$ & $.40^{*}$ & $.48^{*}$ & $.61^{*}$ & $.45^{*}$ & $.75^{*}$ \\
\hline
\end{tabular}
Sources: World Values Survey, Wave 6 (2010-2014), Social Watch (2012), UN Population Division (2010), and Center for Reproductive Rights (2013) ${ }^{*} p<0.001$ (two-tailed) 
Table S4: Generalized Linear Mixed-Effects Multilevel Models with Secularism Predicting Individual-Level CEB, World Values Survey

\begin{tabular}{|c|c|c|c|c|}
\hline & $\begin{array}{c}\text { N/ } \\
\text { (Sub- } \\
\text { sample } \\
\text { Mean } \\
\text { CEB) }\end{array}$ & $\begin{array}{l}\text { Model 1: } \\
\text { With Country- } \\
\text { Level Controls }\end{array}$ & $\begin{array}{c}\text { Model 2: } \\
\text { With Gender } \\
\text { Equity, } \\
\text { Contraception, } \\
\text { and Abortion } \\
\text { Policy }\end{array}$ & $\begin{array}{c}\text { Model 3: } \\
\text { With Gender, } \\
\text { Abortion, and } \\
\text { Autonomy Values }\end{array}$ \\
\hline Full Sample & $\begin{array}{c}83,301 \\
(1.85)\end{array}$ & $\begin{array}{l}-1.43^{* * *} \\
(.25)\end{array}$ & $\begin{array}{c}-1.13^{* * *} \\
(.31)\end{array}$ & $\begin{array}{l}-.45 \\
(.30)\end{array}$ \\
\hline Among Nonreligious Respondents & $\begin{array}{c}15,812 \\
(1.41)\end{array}$ & $\begin{array}{l}-.34 \\
(.19)\end{array}$ & $\begin{array}{l}-.32 \\
(.21)\end{array}$ & $\begin{array}{l}-.10 \\
(.23)\end{array}$ \\
\hline Among Religious Respondents & $\begin{array}{c}67,489 \\
(1.95)\end{array}$ & $\begin{array}{l}-1.68^{* * *} \\
(.25)\end{array}$ & $\begin{array}{l}-1.43^{* * *} \\
(.32)\end{array}$ & $\begin{array}{l}-.77^{*} \\
(.31)\end{array}$ \\
\hline Among Christian Respondents & $\begin{array}{c}34,282 \\
(1.79)\end{array}$ & $\begin{array}{l}-1.05^{* * *} \\
(.22)\end{array}$ & $\begin{array}{l}-.78^{* *} \\
(.23)\end{array}$ & $\begin{array}{l}-.32 \\
(.23)\end{array}$ \\
\hline Among Muslim Respondents & $\begin{array}{c}21,209 \\
(2.20)\end{array}$ & $\begin{array}{l}-1.72^{* * *} \\
(.52)\end{array}$ & $\begin{array}{r}-1.46^{*} \\
(.64)\end{array}$ & $\begin{array}{r}-1.06 \\
(.59)\end{array}$ \\
\hline Among Women & $\begin{array}{c}43,340 \\
(1.96)\end{array}$ & $\begin{array}{l}-1.57^{* * *} \\
(.28)\end{array}$ & $\begin{array}{l}-1.25^{* * *} \\
(.35)\end{array}$ & $\begin{array}{l}-.47 \\
(.34)\end{array}$ \\
\hline Among Men & $\begin{array}{c}39,961 \\
(1.72)\end{array}$ & $\begin{array}{l}-1.25^{* * *} \\
(.23)\end{array}$ & $\begin{array}{l}-.98^{* *} \\
(.29)\end{array}$ & $\begin{array}{l}-.41 \\
(.28)\end{array}$ \\
\hline Among People Aged 44 or Younger & $\begin{array}{c}48,903 \\
(1.28)\end{array}$ & $\begin{array}{l}-.81^{* * *} \\
(.20)\end{array}$ & $\begin{array}{l}-.58^{* *} \\
(.22)\end{array}$ & $\begin{array}{l}-.02 \\
(.20)\end{array}$ \\
\hline Among People Aged 45 or Older & $\begin{array}{c}34,398 \\
(2.65)\end{array}$ & $\begin{array}{l}-2.15^{* * *} \\
(.43)\end{array}$ & $\begin{array}{r}-1.21^{*} \\
(.53)\end{array}$ & $\begin{array}{l}-.32 \\
(.56)\end{array}$ \\
\hline $\begin{array}{l}\text { Among People Aged } 45 \text { or Older } \\
\text { with } 45+\text { Country-Level Secularism }\end{array}$ & $\begin{array}{c}34,398 \\
(2.65)\end{array}$ & $\begin{array}{c}-2.23^{* * *} \\
(.44)\end{array}$ & $\begin{array}{r}-1.26^{*} \\
(.54)\end{array}$ & $\begin{array}{l}-.42 \\
(.56)\end{array}$ \\
\hline $\begin{array}{l}\text { Full Sample, Unaffiliated } \\
\text { as Secularism Measure }\end{array}$ & $\begin{array}{c}83,301 \\
(1.85)\end{array}$ & $\begin{array}{l}-1.07^{* * *} \\
(.23)\end{array}$ & $\begin{array}{l}-.71^{* *} \\
(.23)\end{array}$ & $\begin{array}{l}-.33 \\
(.20)\end{array}$ \\
\hline $\begin{array}{l}\text { Secularism Quadratic: Main Effect } \\
\text { Secularism Squared }\end{array}$ & $\begin{array}{c}83,301 \\
(1.85)\end{array}$ & $\begin{array}{c}-2.54^{* *} \\
(.86) \\
1.35 \\
(1.02)\end{array}$ & $\begin{array}{l}-2.46^{* *} \\
(.96) \\
-1.45 \\
(1.02)\end{array}$ & $\begin{array}{l}-.86 \\
(.97) \\
.34 \\
(.96)\end{array}$ \\
\hline $\begin{array}{l}\text { Linear Mixed-Effects with Multiple } \\
\text { Imputation (20 imputations) }\end{array}$ & $\begin{array}{c}83,301 \\
(1.85)\end{array}$ & $\begin{array}{l}-1.43^{* * *} \\
(.25)\end{array}$ & $\begin{array}{l}-1.12^{* * *} \\
(.31)\end{array}$ & $\begin{array}{l}-.44 \\
(.30)\end{array}$ \\
\hline $\begin{array}{l}\text { Linear Mixed-Effects with Single } \\
\text { Imputation }\end{array}$ & $\begin{array}{c}83,301 \\
(1.85)\end{array}$ & $\begin{array}{c}-1.43^{* * *} \\
(.25)\end{array}$ & $\begin{array}{c}-1.13^{* * *} \\
(.31)\end{array}$ & $\begin{array}{l}-.45 \\
(.30)\end{array}$ \\
\hline
\end{tabular}

Standard errors in parentheses

Sources: World Values Survey, Wave 6 (2010-2014), Social Watch (2012), UN Pop. Division (2010), Center for Reproductive Rights (2013), and KOF (2012)

Note: All models include individual-level controls from Model 2 of Table 2. Individual-level secularism measured in same way as country-level secularism (e.g., quadratic at individual level when quadratic at country level).

${ }^{*} p<0.05,{ }^{* *} p<0.01,{ }^{* * *} p<0.001$ 
Supplemental Materials for Secularism and Fertility Worldwide 10

Table S5: Cross-Level Interaction in Generalized Linear Mixed-Effects Multilevel Models, World Values Survey

\begin{tabular}{lccccc}
\hline & Model 1 & Model 2 & Model 3 & Model 4 & Model 5 \\
\hline Secularism & & & & & \\
Country-Level Secularism & $-2.25^{* * *}$ & $-1.90^{* * *}$ & $-1.68^{* * *}$ & $-1.40^{* * *}$ & $-1.08^{* * *}$ \\
& $(.28)$ & $(.25)$ & $(.31)$ & $(.30)$ & $(.31)$ \\
Individual-Level Secularism & $-.62^{* * *}$ & $-.62^{* * *}$ & $-.62^{* * *}$ & $-.62^{* * *}$ & $-.61^{* * *}$ \\
& $(.05)$ & $(.05)$ & $(.05)$ & $(.05)$ & $(.05)$ \\
Country*Individual Secularism & $1.13^{* * *}$ & $1.13^{* * *}$ & $1.13^{* * *}$ & $1.12^{* * *}$ & $1.11^{* * *}$ \\
& $(.11)$ & $(.11)$ & $(.11)$ & $(.11)$ & $(.11)$ \\
Individual-Level Controls & $\checkmark$ & $\checkmark$ & $\checkmark$ & $\checkmark$ & $\checkmark$ \\
Country-Level Controls & & $\checkmark$ & $\checkmark$ & $\checkmark$ & $\checkmark$ \\
Country-Level Intermediary Factors & & & & $\checkmark$ & $\checkmark$ \\
Material/Structural Factors & & & & $\checkmark$ & $\checkmark$ \\
Gender and Abortion Values & & & & $\checkmark$ & $\checkmark$ \\
Autonomy Values & & & & & $\checkmark$ \\
Constant & .52 & 1.95 & 2.84 & 3.95 & 3.76 \\
\hline Individual-level $N$ & 83,301 & 83,301 & 83,301 & 83,301 & 83,301 \\
Country-level N & 58 & 58 & 58 & 58 & 58 \\
Within $R^{2}$ & .39 & .39 & .39 & .39 & .39 \\
Between $R^{2}$ & .34 & .71 & .76 & .81 & .83 \\
Overall R & .39 & .41 & .41 & .42 & .42 \\
\hline
\end{tabular}

Sources: World Values Survey, Wave 6 (2010-2014), Social Watch (2012), UN Population Division (2010), and Center for Reproductive Rights (2013)

Controls and intermediary factors included in models parallel those in Table 2.

Standard errors in parentheses; ${ }^{*} p<0.05,{ }^{* *} p<0.01,{ }^{* * *} p<0.001$ 